\title{
Advanced Exergy Analysis for a Novel Gasoline Absorption-Stabilization Process
}

\author{
Lei, Yang; Chen, Yuqiu; Yang, Yibo; Liu, Xinyan; Luo, Hao; Yan, Wei
}

Published in:

ACS Omega

Link to article, DOI:

10.1021/acsomega.1c01658

Publication date:

2021

Document Version

Publisher's PDF, also known as Version of record

Link back to DTU Orbit

Citation $(A P A)$ :

Lei, Y., Chen, Y., Yang, Y., Liu, X., Luo, H., \& Yan, W. (2021). Advanced Exergy Analysis for a Novel Gasoline Absorption-Stabilization Process. ACS Omega, 6(23), 15332-15347. https://doi.org/10.1021/acsomega.1c01658

\section{General rights}

Copyright and moral rights for the publications made accessible in the public portal are retained by the authors and/or other copyright owners and it is a condition of accessing publications that users recognise and abide by the legal requirements associated with these rights.

- Users may download and print one copy of any publication from the public portal for the purpose of private study or research.

- You may not further distribute the material or use it for any profit-making activity or commercial gain

- You may freely distribute the URL identifying the publication in the public portal

If you believe that this document breaches copyright please contact us providing details, and we will remove access to the work immediately and investigate your claim. 


\title{
Advanced Exergy Analysis for a Novel Gasoline Absorption- Stabilization Process
}

\author{
Yang Lei,* Yuqiu Chen, Yibo Yang, Xinyan Liu, Hao Luo, and Wei Yan*
}

Cite This: ACS Omega 2021, 6, 15332-15347

Read Online

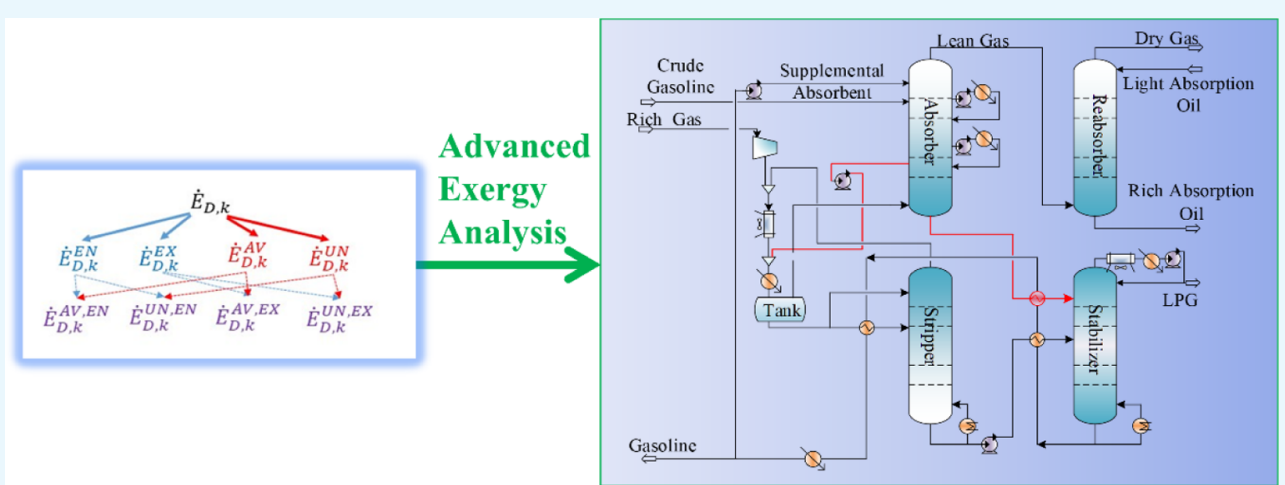

ABSTRACT: The advanced exergy analysis can identify the improved potential of each component and the interaction among components of the refining processes. In this work, a new gasoline absorption-stabilization process (GASP) is proposed for better energy utilization considering the absorption process intensification, which can be further explained using exergy analysis. Both conventional and new GASPs are simulated in PRO/II, which are verified with the actual plant operation data. The energy performance of both conventional and new GASPs is evaluated through the advanced exergy analysis. The exergy efficiencies of conventional and new GASPs are 65.04 and $71.44 \%$, respectively. In addition, the total exergy destruction rates are 7.79 and 6.01 MW, respectively. The total exergy destructions of 46.37 and $40.73 \%$ can be reduced, respectively. Though the stabilizer has the largest exergy destruction in both the processes, the air cooler for the rich gas in the new GASP has the largest potential for reducing exergy destruction, which is different from the conventional GASP. Furthermore, a sensitivity analysis of the new GASP is performed to study the effects of newly added operation and design parameters on the conventional and advanced exergy analyses of the absorber.

\section{INTRODUCTION}

As a core operation in crude oil refining, gasoline absorptionstabilization processes (GASPs) are widely applied for the separation of gasoline from refinery mixtures. ${ }^{1}$ There is more than 140 million tons of gasoline throughput in China. ${ }^{2}$ The feeds to GASPs are crude gasoline and rich gas from the main fractionators in fluid catalytic cracking units (FCCUs) or delayed coking units (DCUs). ${ }^{3}$ The products are dry gas, liquefied petroleum gas (LPG), and stabilized gasoline. A conventional GASP contains four columns and two recycling streams, resulting in a rather complex process with high total annual cost (TAC). It is desirable but challenging to intensify and simplify this complex process. Many studies have focused on process intensification and simplification for a better economic, environmental, and energy efficiency performance. ${ }^{1,4}$ Liu et al. ${ }^{4}$ proposed a new absorption-stabilization process with a twostage condensation to improve energy performance. In the new process, a condenser, a condensed oil tank, and a side reboiler were integrated into the original process and then a heat integration scheme. Compared with the conventional process, the proposed process could achieve high energy efficiency.

Exergy analysis can identify the sources, magnitude, and location of thermodynamic inefficiencies in a system, which provides the critical information for improving the overall system efficiency by focusing on the worst exergy balance components. ${ }^{5}$ Chen et al. ${ }^{6}$ used exergy and exergoeconomic analysis method to tackle the expansion and energy utilization problems of an aromatic hydrocarbon separation plant. Then, they ${ }^{7}$ pointed out based on an exergy analysis that there was a great potential for energy-saving by improving the heat removals of the main fractionator in DCUs. Different from conventional

Received: March 28, 2021

Accepted: May 20, 2021

Published: May 28, 2021

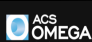

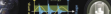




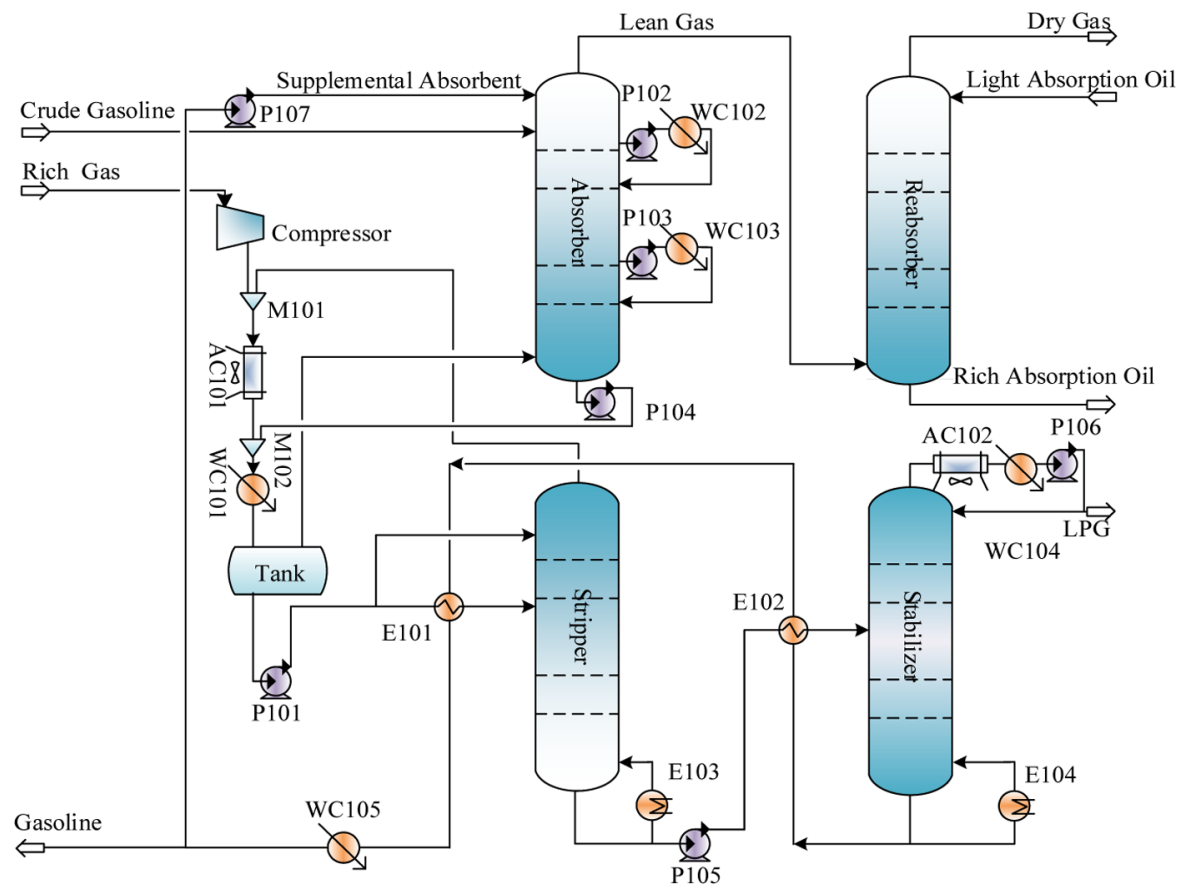

Figure 1. Process flow diagram (PFD) for a conventional GASP.

analysis methods, ${ }^{8}$ the advanced exergy analysis is an efficient approach to identify the internal or external sources of irreversibilities in the system components. It has many benefits for detailed analysis of energy conversion systems. The main role of an advanced analysis is to provide the designers and operators for energy conversion systems with useful information for improving the design and operation of such systems.

Splitting exergy destruction into endogenous and exogenous parts improves our understanding of the interactions among the system components, particularly when this concept is combined with the concept of avoidable and unavoidable exergy destructions. ${ }^{9}$ The advanced exergy analysis is widely used in evaluating and optimizing individual equipment (e.g., fractionator, ${ }^{10}$ compressor, ${ }^{11}$ internal combustion engine, ${ }^{12}$ biomass boiler, ${ }^{13}$ industrial boiler, ${ }^{14}$ gasifier, ${ }^{15}$ and wind turbine ${ }^{16}$ ) and processes. ${ }^{17-47}$ Exergy analysis is widely applied to evaluate the thermodynamic performance of the power generation processes in the beginning ${ }^{17-38}$ and then expanded to the other fields such as petroleum-based or coal-based chemical processes. ${ }^{39-47}$ The major difference between the former and the latter applications is whether the process streams undergo multicomponent phase separation and reaction. Chang and $\mathrm{Li}^{39}$ proposed a two-level idealization concept involving the definition of intrinsic and extrinsic exergy destruction to incorporate into exergy analysis, exergoeconomic analysis, and optimization, and it was demonstrated by an ethylene product recovery and separation plant together with a benzene-toluene distillation column. Wei et al. $^{40}$ presented an exergy analysis and an exergoeconomic evaluation to identify the energy-saving potentials in distillation processes, and it was applied to analyze the energy utilization performance of a light-end separation plant. Yang et al. ${ }^{41}$ applied the advanced exergy analysis to evaluate the performance of a Fushun-type oil shale retorting process. The retort had the greatest potential for decreasing the exergy destruction. Mehrpooya et al. $^{42}$ presented an advanced exergy analysis of the ethane recovery plant in the South Pars gas field. An industrial refrigeration cycle with a propane refrigerant was investigated by the exergy analysis method. Yamankaradeniz ${ }^{43}$ assessed the thermodynamic performance of a geothermal district heating system using advanced exergy analysis to identify the interactions among system components and the potential for improvement. Vatani et al. ${ }^{44}$ performed advanced exergy analysis for five mixed refrigerant LNG processes, and four parts of irreversibility (avoidable/unavoidable and endogenous/ exogenous) were calculated for the components with high inefficiencies. The results showed that a portion of endogenous exergy destruction in the components was higher than the exogenous one. He et $a l^{45}$ applied conventional and advanced exergy analyses to evaluate the compressed air energy storage and supercritical compressed $\mathrm{CO}_{2}$ energy storage performances. Ghorbani and Roshani ${ }^{46}$ applied the advanced exergoeconomic analysis on process configurations for co-production of liquefied natural gas and natural gas liquids. Li et al. ${ }^{47}$ simulated the ash agglomerating fluidized bed gasification process in Aspen Plus. The advanced exergy analysis was carried out to study the performance of the process based on the simulation result. The result showed that the AFB gasifier had the largest potential for reducing exergy destruction.

As the core operation in crude oil refining with high energy consumption, new GASPs are usually proposed to improve the energy performance by process innovation and operating parameter optimization. ${ }^{1,4}$ Rare publications address intensification and improvement of GASPs for better energy efficiency by using the advanced exergy analysis. Furthermore, the advanced exergy analysis can identify the improved potential of each component and the interaction among components of the petroleum-based chemical processes compared with the conventional exergy analysis. ${ }^{15,40-42}$ The energy utilization bottlenecks of the conventional and new processes and energysaving potentials of components may be different. The effects of newly added operation and design parameters on exergy destruction should be evaluated in the new process. It is important to use advanced exergy analysis for understanding the energy performance of the new process to compare with that of 


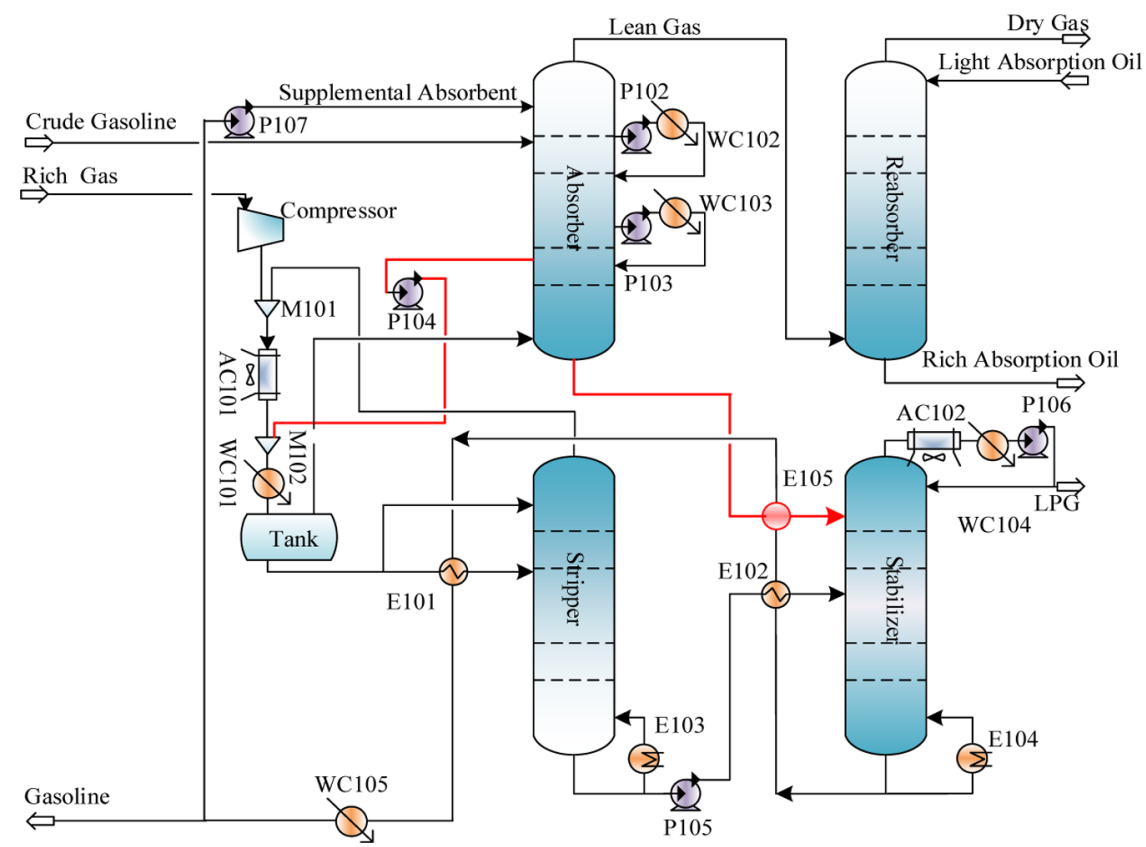

Figure 2. PFD for a new GASP.

the conventional process. Therefore, in this work, the energy efficiency in GASPs was improved through two aspects: the process innovation based on the absorption process intensification and thermodynamic evaluation by means of process simulation and exergy analysis. First, the GASP was modified by adding the side draw of the absorber. Both conventional and new GASPs are simulated by PRO/II. Second, advanced exergy analysis was applied to evaluate both the conventional and new retrofit GASPs in order to evaluate the advantages of the new GASP. The exergy destruction rates were calculated including avoidable/unavoidable and endogenous/exogenous parts for all components in the processes. Finally, sensitivity analysis of the new GASP was performed to study the effects of newly added operation and design parameters on exergy destruction.

\section{DESCRIPTION AND ANALYSIS OF A NEW GASP FOR ENERGY-EFFICIENT UTILIZATION}

A conventional GASP of a refinery in South China is shown in Figure 1 including an absorber, a reabsorber, a stripper, and a stabilizer with other auxiliary equipment. The compressed rich gas from the top of the main fractionators of FCCUs or DCUs is first mixed with the desorbed gas from the stripper and the rich absorption oil from the absorber. After being cooled to about $313 \mathrm{~K}$, the mixture is separated into gaseous and liquid phases through flowing into a condensed oil tank. The gaseous and liquid streams out of the tank are fed into the bottom of the absorber and the top of the stripper, respectively. Then, crude gasoline and a portion of stable gasoline enter the top of the absorber as the main absorbent and supplementary absorbent, respectively. The heat released from the absorber is removed by two side heat removal coolers. The lean gas coming out from the top of the absorber is fed directly into the bottom of the reabsorber. To recover dry gas $\left(\mathrm{C}_{2-}\right.$ components $)$ and residual gasoline from the lean gas, light diesel oil is simultaneously introduced into the top of the reabsorber as the absorbent. Meanwhile, the liquid stream from the tank is split into two streams as double feeds of the stripper. One stream (around onethird of the liquid stream from the tank) is directly fed into the top of the stripper, and the other is preheated to $363 \mathrm{~K}$ and enters the intermediate section of the stripper. The bottom product of the stripper is preheated to $408 \mathrm{~K}$ and enters the upper part of the stabilizer, where LPG and stable gasoline products are recovered from its top and bottom, respectively. Finally, the stable gasoline is cooled to $313 \mathrm{~K}$ by exchanging heat with cooling water. A small portion of the stable gasoline (accounting for about a quarter of the stable gasoline) is recycled to the absorber, and the remaining stable gasoline is considered as the final product.

Through the analysis of the composition of stripping gas, it is found that there are more than a third of components $\mathrm{C}_{3}-\mathrm{C}_{5}$ always present in the cycle stream between the absorber and the stripper. This is unfavorable in terms of energy utilization since repeated cooling and heating (with phase transition) cause nonnegligible energy consumption. Combined with the absorption process mechanism, due to the different solubility of each component in the absorber, the distribution of components in the absorber is that components $\mathrm{C}_{1}$ and $\mathrm{C}_{2}$ are absorbed rapidly on the upper stages of the absorber, components $\mathrm{C}_{4}$ and $\mathrm{C}_{5}$ are absorbed rapidly on the lower stages of the absorber, while components $\mathrm{C}_{3}$ are absorbed steadily in the whole column.

Based on the above analysis, a new GASP is proposed to reduce the repeated cooling and heating that cause exergy destruction. A novel and energy-saving flow sheet is proposed in which there is a side draw stream in the absorber to mix the rich gas and the stripping gas. The side draw stream is cooled into the flash tank, and the bottom stream flows into the stabilizer directly as shown in Figure 2. As a result, the liquid flow rate from the flash tank and components $\mathrm{C}_{4}$ and $\mathrm{C}_{5}$ from stripping gas are reduced to save the heat duty of the reboiler in the stripper. A new heat exchanger (E105) between the absorber bottom oil and stabilized gasoline has been applied. The rich gas and the top gaseous stream in the stripper are cooled by an air cooler before being mixed with liquid side draw in the absorber. After being heated by the stable gasoline, the bottom stream of the absorber is directly fed into the upper part of the stabilizer. Compared with the conventional process, the new energy-saving 
process has more parameters to manipulate, such as the flow rate and location of the side draw of the absorber, and the temperature and location of the stream fed into the stabilizer from the bottom of the absorber. It is worth noting that there is very little modification of the new process. Inevitably, the retrofit of the new energy-saving process will increase the investment cost of the heat changer and the pipeline, which are far less than the benefit of energy savings.

\section{METHOD FOR THE ANALYSIS AND EVALUATION OF THE GASP}

3.1. Process Simulation of the GASP. PRO/II (version 9.4) is applied for calculating the mass, energy, and exergy balance of GASPs as shown in Figures 1 and 2. The physical properties in the GASPs are estimated by using the SoaveRedlich-Kwong equation with API correlations applied to calculate the liquid density. ${ }^{1,4}$ The simulations of conventional and new processes are based on the industrial data of the GASP in a Chinese refinery such as the composition and flow rate of the feed, the design variables of the equipment, separation requirement, and so forth.

3.2. Conventional Exergy Analysis. Exergy analysis is employed to calculate the maximum useful power accessible by an assigned amount of input energy to a background process. Neglecting the effects of kinetic, potential, and nuclear energies (unchanged or insignificant), the total exergy can be divided into two parts (chemical and physical exergies). Equations 1-3 express the total exergy, the physical exergy, and the chemical exergy, respectively ${ }^{42}$

$$
\begin{aligned}
& \dot{E}=\dot{E}^{\mathrm{ph}}+\dot{E}^{\mathrm{ch}} \\
& \dot{E}^{\mathrm{ph}}=\left(\dot{H}-\dot{H}_{0}\right)-T_{0}\left(\dot{S}-\dot{S}_{0}\right) \\
& \dot{E}^{\mathrm{ch}}=\sum x_{i} \dot{E}_{i}^{0}+\Delta \dot{G}^{\mathrm{mix}}
\end{aligned}
$$

where $\dot{H}_{0}$ and $\dot{S}_{0}$ are the enthalpy and entropy rates at $298 \mathrm{~K}$ and $0.1 \mathrm{MPa}$ and $\dot{H}$ and $\dot{S}$ refer to the enthalpy and entropy rates at a given temperature and pressure, respectively. The data of $\dot{H}_{0}, \dot{H}$, and $\dot{S}$ are calculated by PRO/II.

The $\dot{E}^{\text {ch }}$ of gaseous and non-gaseous mixtures can be written as eqs 4 and 5

$$
\begin{aligned}
& \dot{E}^{\mathrm{ch}}=R T_{0} \sum x_{i} \ln x_{i}+\sum x_{i} \dot{E}_{0, i}^{\mathrm{CH}} \\
& \dot{E}^{\mathrm{ch}}=\sum x_{i} \dot{E}_{0, i}^{\mathrm{CH}}
\end{aligned}
$$

where $\dot{E}_{0, i}^{\mathrm{CH}}$ is the component's standard chemical exergy rate, $x_{i}$ refers to the component's molar fraction, $R$ is $8.314 \mathrm{~kJ} \cdot \mathrm{kmol}^{-1}$. $\mathrm{K}^{-1}$, and the subscript 0 stands for the reference state $(298 \mathrm{~K}$ and $0.1 \mathrm{MPa}$ ).

The exergy destruction rate, exergy destruction ratio, and exergy efficiency are important parameters in exergy analysis. Equations 6-9 express the exergy balance and exergy efficiency for the $k$ th component ${ }^{9}$

$$
\begin{aligned}
& \dot{E}_{\mathrm{F}, k}=\dot{E}_{\mathrm{P}, k}+\dot{E}_{\mathrm{D}, k} \\
& \varepsilon_{k}=\frac{\dot{E}_{\mathrm{P}, k}}{\dot{E}_{\mathrm{F}, k}}=1-\frac{\dot{E}_{\mathrm{D}, k}}{\dot{E}_{\mathrm{F}, k}} \\
& \dot{E}_{\mathrm{in}, k}=\dot{E}_{\mathrm{out}, k}+\dot{E}_{\mathrm{D}, k}
\end{aligned}
$$

$$
\eta_{k}=\frac{\dot{E}_{\text {out }, k}}{\dot{E}_{\text {in }, k}}
$$

Equations 10 and 11 express ratios of the exergy destruction rate within the $k$ th component to the total exergy rate of the feed and exergy destruction rate of the system.

$$
\begin{gathered}
y_{k}=\frac{\dot{E}_{\mathrm{D}, k}}{\dot{E}_{\mathrm{F}, \text { tot }}} \\
y_{k}^{*}=\frac{\dot{E}_{\mathrm{D}, k}}{\dot{E}_{\mathrm{D}, \text { tot }}}
\end{gathered}
$$

3.3. Advanced Exergy Analysis. The conventional exergy analysis cannot identify the portion of inefficiencies that can be avoided as well as the portion of exergy destruction produced through the performance of a component alone. In contrast, the advanced exergy analysis can estimate the interactions among the components and reveal technological limitations on the efficiency of a process. ${ }^{41}$ Exergy destruction can be split into unavoidable/avoidable and exogenous/endogenous parts by the advanced exergy analysis as shown in Figure 3. Mixing these two

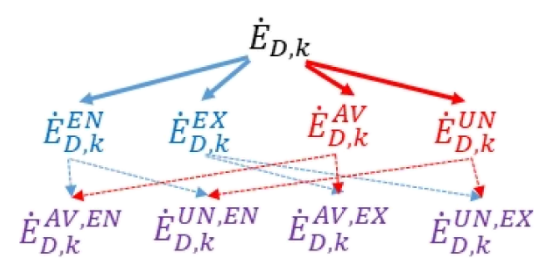

Figure 3. Options for splitting exergy destruction in the $k$ th component.

options, exergy destruction is categorized as four parts including unavoidable/endogenous, unavoidable/exogenous, avoidable/ endogenous, and avoidable/exogenous exergy destructions.

3.3.1. Avoidable and Unavoidable Exergy Destructions. As aforementioned, the technical and economical limitations include certain barriers that constitute a part of unavoidable irreversibilities. Focusing on the avoidable irreversibilities, it is adequate to define the total exergy destruction for the $k$ th component of a process as eq 12

$$
\dot{E}_{\mathrm{D}, k}=\dot{E}_{\mathrm{D}, k}^{\mathrm{AV}}+\dot{E}_{\mathrm{D}, k}^{\mathrm{UN}}
$$

The unavoidable conditions are assumed based on the knowledge and experience to consider the maximum improvement potential, which may be achieved in the future prospectively. Additionally, efficiency improvement lowers the exergy production and energy consumption in equipment. However, the capital costs of a plant are increased when conventional equipment is replaced with a more efficient one. The unavoidable irreversibility is calculated as eq 13

$$
\dot{E}_{\mathrm{D}, k}^{\mathrm{UN}}=\dot{E}_{\mathrm{P}, k}\left(\frac{\dot{E}_{\mathrm{D}}^{\mathrm{UN}}}{\dot{E}_{\mathrm{P}}}\right)_{k}
$$

The unavoidable exergy destruction rate per unit of the produced exergy rate of the $k$ th component is calculated by the expression $\left(\dot{E}_{\mathrm{D}}^{\mathrm{UN}} / \dot{E}_{\mathrm{P}}\right)_{k}$. The produced exergy rate is shown by $\dot{E}_{\mathrm{P}}$. The exergy efficiency of the component is calculated by two critical models. The first one is the output/input that defines the exergy efficiency as the ratio of exergy of output streams to 
Table 1. Exergy Calculation in Each Component of the System

\begin{tabular}{|c|c|c|c|c|}
\hline Components & Schematic view & $\dot{E}_{F, k}$ & $\dot{E}_{P, k}$ & $\dot{E}_{D, k}$ \\
\hline Absorption & & $\dot{E}_{1, A b C}-\dot{E}_{2, A b C}$ & $\dot{E}_{4, A b C}-\dot{E}_{3, A b C}$ & $\dot{E}_{F, A b C}-\dot{E}_{P, A b C}$ \\
\hline Distillation & & $\dot{E}_{1, \mathrm{DiC}}$ & $\dot{E}_{2, D i C}+\dot{E}_{3, D i C}$ & $\dot{E}_{F, D C}-\dot{E}_{P, D i C}$ \\
\hline Flash tank & & $\dot{E}_{1, F l}$ & $\dot{E}_{2, F l}+\dot{E}_{3, F l}$ & $\dot{E}_{F, F l}-\dot{E}_{P, F l}$ \\
\hline Heat & & $\dot{E}_{1, \mathrm{HeEx}}-\dot{E}_{2, \mathrm{HeEx}}$ & $\dot{E}_{4, \mathrm{HeEx}}-\dot{E}_{3, \mathrm{HeEx}}$ & $\dot{E}_{F, H e E x}-\dot{E}_{P, H e E x}$ \\
\hline exchanger & & & & \\
\hline Compressor & & W & $\dot{E}_{2, C o}-\dot{E}_{1, C o}$ & $\dot{E}_{F, C o}-\dot{E}_{P, C o}$ \\
\hline Pump & & W & $\dot{E}_{2, P u}-\dot{E}_{1, P u}$ & $\dot{E}_{F, P u}-\dot{E}_{P, P u}$ \\
\hline Mixer & & $\dot{E}_{1, M}+\dot{E}_{2, M i}$ & $\dot{E}_{3, M i}$ & $\dot{E}_{F, M i}-\dot{E}_{P, M i}$ \\
\hline
\end{tabular}

exergy of inlet streams. The second model is consumed/ produced, which defines the exergy efficiency as the ratio of the produced exergy to the consumed exergy. As an illustration, the exergy of input work to the component such as a compressor is considered as consumed exergy and the exergy product is the difference between exergy of the input and output streams. In this study, the analysis is performed by the consumed/produced model. Values of the unavoidable conditions are considered with the assumptions that are carried out in the different publications. It is clear that exergy destruction and energy consumption of a component with high efficiency are lower than conventional instruments. However, using the units with high efficiency can increase the capital cost. Therefore, because of the technical and economical limitations, the efficiency of the equipment cannot increase above a certain value. The definitions of the feed exergy rates, product exergy rates, and exergy destruction rates of different components in the GASP have been discussed in detail $^{45}$ and are listed in Table 1.

3.3.2. Endogenous and Exogenous Exergy Destructions. $\dot{E}_{\mathrm{D}, k}$ of the $k$ th component can be divided into $\dot{E}_{\mathrm{D}, k}^{\mathrm{EN}}$ and $\dot{E}_{\mathrm{D}, k}^{\mathrm{EX}}$

$$
\dot{E}_{\mathrm{D}, k}=\dot{E}_{\mathrm{D}, k}^{\mathrm{EN}}+\dot{E}_{\mathrm{D}, k}^{\mathrm{EX}}
$$

$\dot{E}_{\mathrm{D}, k}^{\mathrm{EN}}$ is caused by the irreversibility taking place in the $k$ th component when the remaining components operate in a reversible way and the $k$ th component operates with its current efficiency. $\dot{E}_{\mathrm{D}, k}^{\mathrm{EX}}$ is caused by the irreversibilities occurred in all the other components. The endogenous irreversibility is the main concern of the advanced exergy analysis. The following methods are used to calculate the endogenous irreversibility of a component: ${ }^{19}(1)$ an approach based on thermodynamic cycles,
(2) an engineering approach, (3) an exergy balance method, (4) an equivalent component method, and (5) a structural theory.

In this work, practical conditions are used for the conventional exergy analysis. $\dot{E}_{\mathrm{D}, k}^{\mathrm{EN}}$ and $\dot{E}_{\mathrm{D}, k}^{\mathrm{EX}}$ are calculated with the theoretically optimal conditions. $\dot{E}_{\mathrm{D}, k}^{\mathrm{AV}}$ and $\dot{E}_{\mathrm{D}, k}^{\mathrm{UN}}$ are calculated using the defined maximum permissible values, that is, theoretically optimal and practically feasible operating conditions. The product exergy for the whole system is assumed to be constant. Real operation conditions (ROCs) are realistic currently achievable operation performance data for all components of the observed energy system, for example, actual thermodynamic efficiency. Unavoidable operation conditions (UOCs) are also realistic operation data, but achievable only in perspective, that is, in the future. Unavoidable operating conditions are those that cannot be achieved in a foreseeable or near future with current trends of the technological development. Their choice is arbitrary to some extent and depends on decision makers and their understanding of processes and theoretical backgrounds, as well as following current scientific and practical achievements. They are important when formulating the foreseen potential for further improvements of each component and accordingly determining the unavoidable part of exergy destruction. Establishing UOCs for each component requires the forecasts of the development tendencies and achievements for that type of the component. Theoretical operation conditions (TOCs) of components cannot be achieved in practice. They are based on the assumption of the ideal operation, for example, with maximal theoretical efficiency. TOCs are used to calculate endogenous and exogenous exergy destructions. The summary of assumptions of ROCs, UOCs, and TOCs based on the adopted 
Table 2. Comparison for Mass Balance in the Simulation

\begin{tabular}{|c|c|c|c|c|c|c|}
\hline \multirow[b]{2}{*}{ items } & & \multirow[b]{2}{*}{$\begin{array}{l}\text { industrial } \\
\text { data } / \mathrm{kg} \cdot \mathrm{h}^{-1}\end{array}$} & \multicolumn{2}{|c|}{ conventional GASP } & \multicolumn{2}{|c|}{ new GASP } \\
\hline & & & $\begin{array}{l}\text { simulation } \\
\text { results } / \mathrm{kg} \cdot \mathrm{h}^{-1}\end{array}$ & $\begin{array}{l}\text { relative errors }^{a} \\
(\%)\end{array}$ & $\begin{array}{l}\text { simulation } \\
\text { results } / \mathrm{kg} \cdot \mathrm{h}^{-1}\end{array}$ & $\begin{array}{l}\text { relative errors }^{a} \\
(\%)\end{array}$ \\
\hline \multirow[t]{4}{*}{ feeds } & rich gas & 46,200 & 46,200 & 0.00 & 46,200 & 0.00 \\
\hline & naphtha & 65,800 & 65,800 & 0.00 & 65,800 & 0.00 \\
\hline & complementary absorbent & 26,900 & 25,387 & 5.62 & 25,481 & 5.28 \\
\hline & light absorption oil & 14,200 & 14,200 & 0.00 & 14,200 & 0.00 \\
\hline \multirow[t]{4}{*}{ products } & dry gas & 9000 & 10,036 & 11.51 & 10,038 & 11.53 \\
\hline & LPG & 25,500 & 27,650 & 8.43 & 27,661 & 8.47 \\
\hline & $\begin{array}{l}\text { gasoline (including a complementary } \\
\text { absorbent) }\end{array}$ & 102,500 & 98,093 & 4.30 & 98,043 & 4.35 \\
\hline & rich absorbent & 16,100 & 15,808 & 1.81 & 15,939 & 1.00 \\
\hline
\end{tabular}

${ }^{a}$ Relative errors $=\mid$ simulation results - practical datal $/$ ref. $\times 100 \%$.

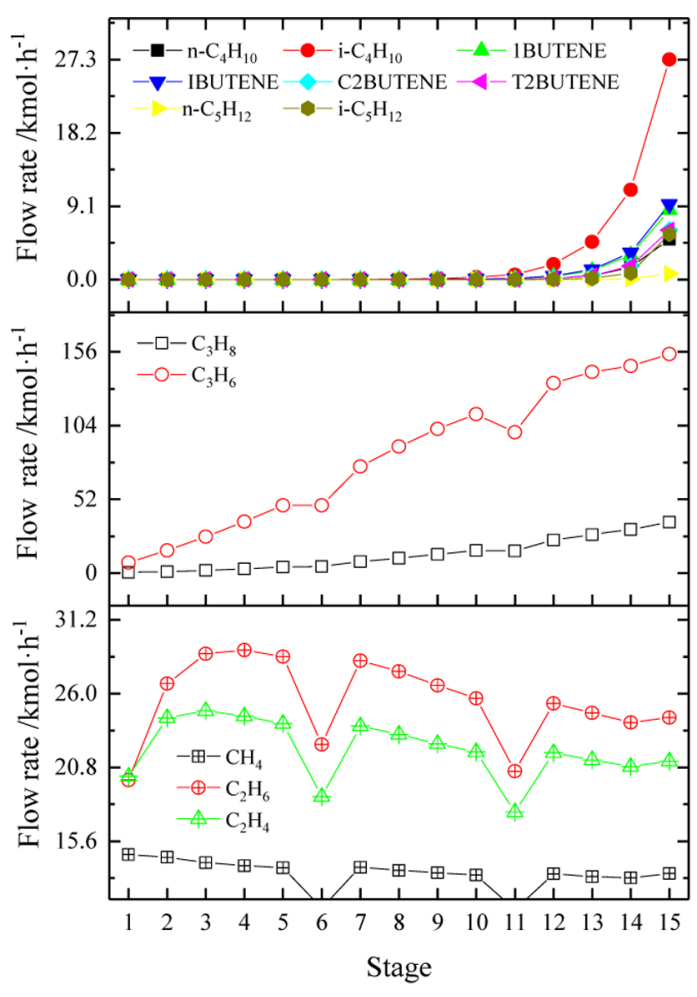

a. Conventional GASP.

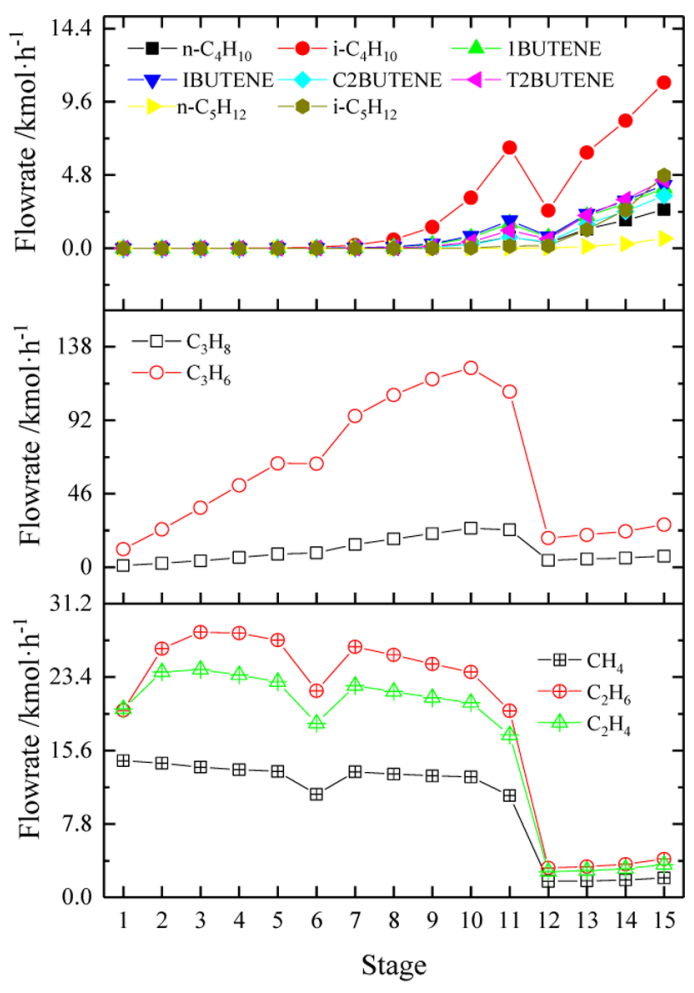

b. New GASP.

Figure 4. $C_{1}-C_{5}$ composition distribution in the liquid of the absorber.

approach is given in Table $S 1$ for the components of the system. $^{25}$

3.3.3. Combing the Splitting Methods. To calculate the unavoidable endogenous part of the exergy destruction rate within the $k$ th component, the ratio of exergy destruction to product exergy of this component in its UOCs and the product exergy of it in its hybrid cycle should be obtained as follows

$$
\dot{E}_{\mathrm{D}, k}^{\mathrm{UN}, \mathrm{EN}}=\dot{E}_{\mathrm{P}, k}^{\mathrm{EN}}\left(\frac{\dot{\mathrm{E}}_{\mathrm{D}}^{\mathrm{UN}}}{\dot{\mathrm{E}}_{\mathrm{P}}}\right)_{k}
$$

The unavoidable exogenous part of the exergy destruction rate is calculated with a combination of eqs 12 and 15

$$
\dot{E}_{\mathrm{D}, k}^{\mathrm{UN}, \mathrm{EX}}=\dot{E}_{\mathrm{D}, k}^{\mathrm{UN}}-\dot{E}_{\mathrm{D}, k}^{\mathrm{UN}, \mathrm{EX}}
$$

Then, avoidable endogenous and exogenous parts of the exergy destruction rates are calculated by subtracting unavoid- able endogenous and exogenous exergy destruction rates, respectively, from the total endogenous and exogenous exergy destruction rates.

$$
\begin{aligned}
& \dot{E}_{\mathrm{D}, k}^{\mathrm{AV}, \mathrm{EN}}=\dot{E}_{\mathrm{D}, k}^{\mathrm{EN}}-\dot{E}_{\mathrm{D}, k}^{\mathrm{UN}, \mathrm{EN}} \\
& \dot{E}_{\mathrm{D}, k}^{\mathrm{AV}, \mathrm{EX}}=\dot{E}_{\mathrm{D}, k}^{\mathrm{EX}}-\dot{E}_{\mathrm{D}, k}^{\mathrm{UN}, \mathrm{EX}}
\end{aligned}
$$

\section{RESULTS AND DISCUSSION}

4.1. Results of Simulation. The primary models for each component are demonstrated in Table 1 for both conventional and new GASPs. The tray data, specification, and variable parameters of columns are given in Table S2. ${ }^{1,4}$ The mass balance of practical operation and simulation are given in Table 2. The main parameters are compared in Table S3. The relative error of the dry gas is relatively high, which is probably due to the limitation of the thermodynamic model used in the simulation. 


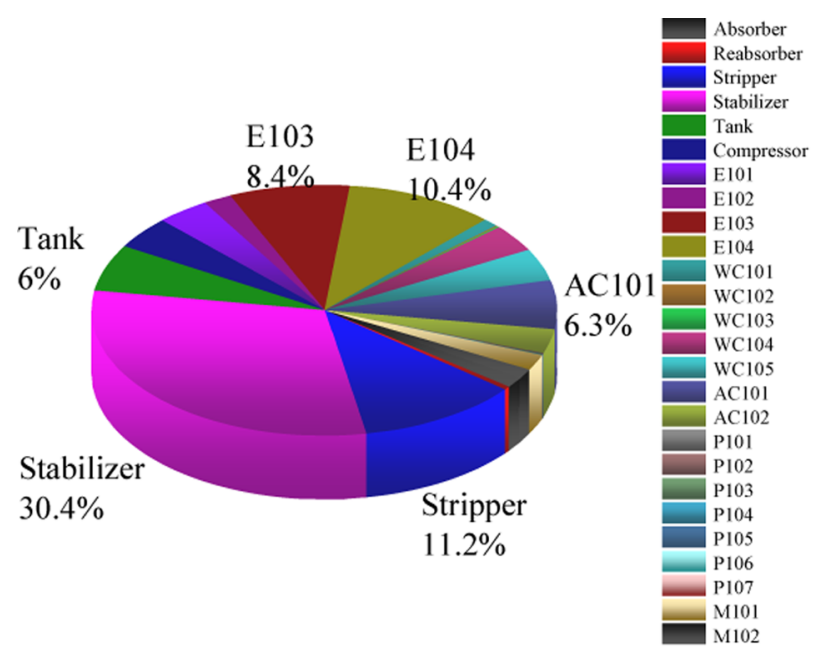

a. conventional GASP.

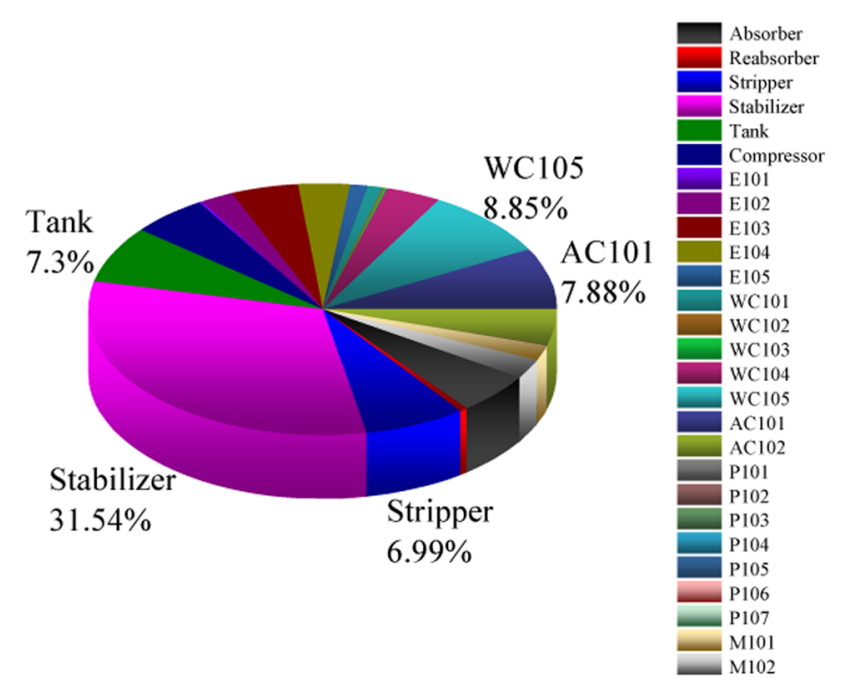

b. new GASP.

Figure 5. Exergy destruction ratios for conventional and new GASPs.

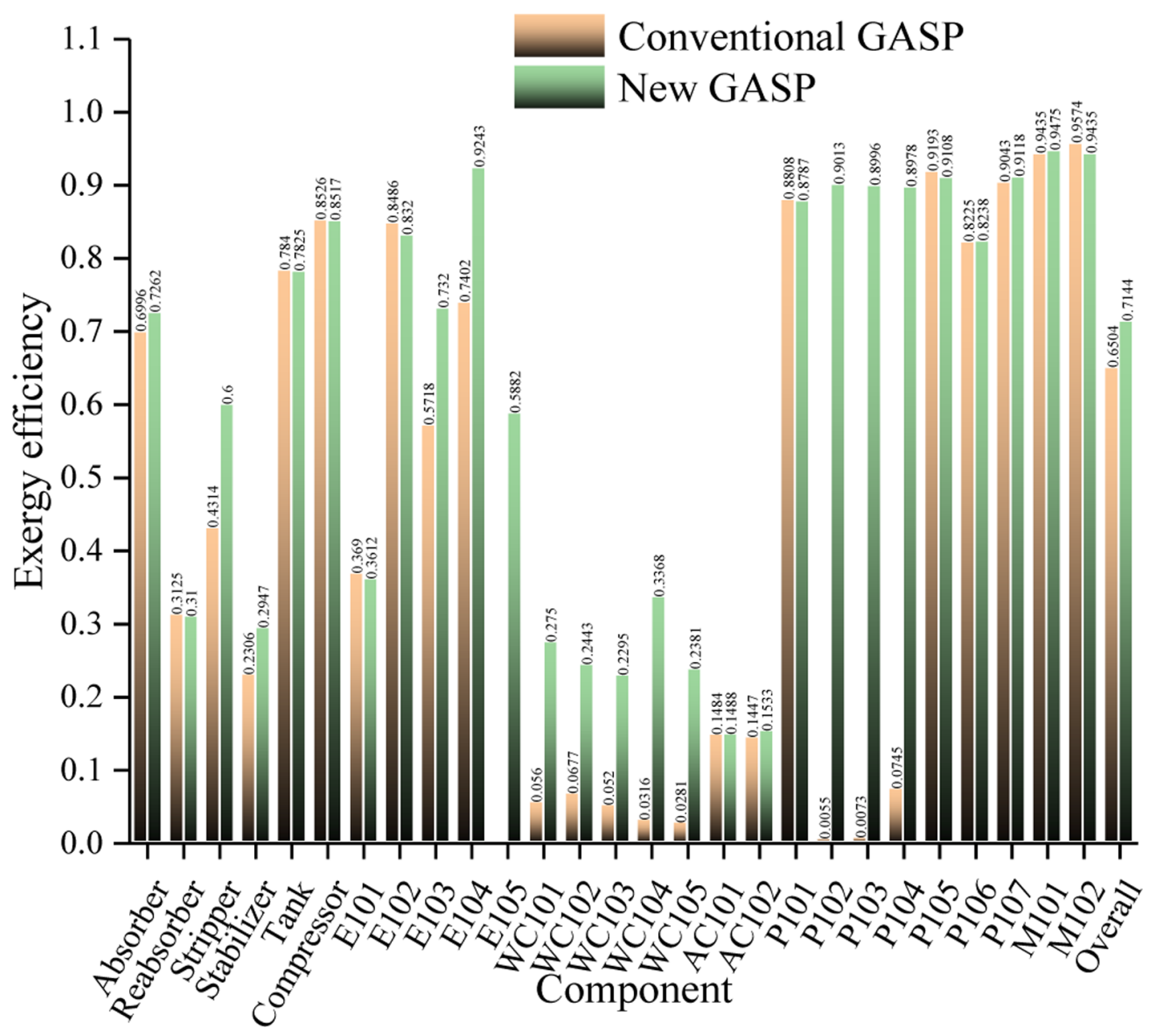

Figure 6. $\varepsilon_{k}$ for components in conventional and new GASPs.

The system contains not only light hydrocarbons but also pseudo-components which are characterized using the ASTM D86 assay data. It should be noted that the dry gas is just a small portion of products (nearly 4.60\%). The simulation results are considered acceptable in comparison with the industrial data.
Hot utilities are employed in the reboilers of the stripper (E103) and stabilizer (E104). Meanwhile, cold utilities are employed in AC101, WC101, WC102, WC103, AC102, WC104, and WC105. The total energy consumption can be saved through heat integration. Following notes should be 


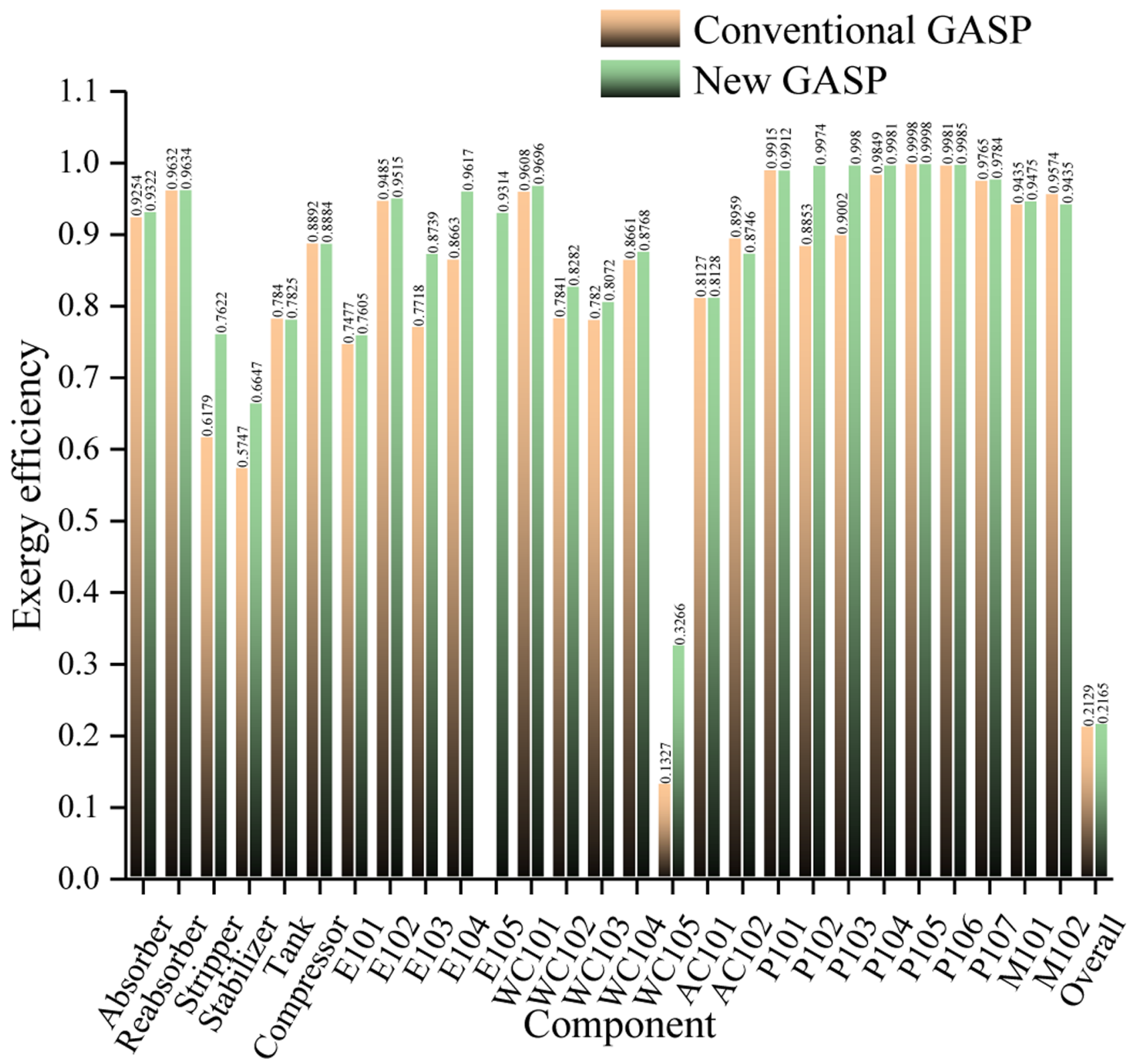

Figure 7. $\eta_{k}$ for components in conventional and new GASPs.

mentioned for the comparison of two processes: (1) heat removals of the absorber remain the same (WC102 and WC103), (2) the heat duty of the gasoline cooled by the cold utility remains the same (WC105), and (3) the heat duty of E102 in the conventional GASP is the same with that of E102 and E105 in the new GASP. The comparison for main energy consumption components of two processes is shown in Figure $\mathrm{S} 1$ on the premise of the same flow rates and purities for both feeds and products.

Compared with the conventional GASP, the energy consumption of the new GASP is reduced by $5.20 \%$. The comparison of vapor-liquid duty of the stripper is shown in Figure S2. Vapor-liquid duty in the stripper of the new GASP is lower than that of the conventional GASP. The stripper is to separate out $\mathrm{C}_{2-}$ components. The decrease of those components can reduce the heat duty of the reboiler significantly because the latent heat of the vaporization is enormous. In addition, the second theoretical tray has the hot feed of the liquid phase, and there is a sudden change for the liquid duty. To verify the energy-saving mechanism of the new GASP, the $\mathrm{C}_{1}-$ $\mathrm{C}_{5}$ composition distributions in the liquid of the absorber are compared for the conventional and new GASPs. As shown in Figure 4 , the $C_{4}-C_{5}$ concentration gradient becomes smaller from the side draw tray to the bottom tray in the absorber. Meanwhile, the $\mathrm{C}_{1}-\mathrm{C}_{2}$ concentration gradient increases from the side draw tray to the bottom tray in the absorber. $\mathrm{C}_{3}$ concentration gradients are basically the same over the whole column.

4.2. Results of Conventional Exergy Analysis. Based on the exergy balance, a detailed conventional exergy analysis is performed as shown in Table S4. For the overall system, the $\dot{E}_{\text {input,System }} / \dot{E}_{\text {output,System }}$ values of conventional and new GASPs are $8.3685 / 1.7816$ and $8.2204 / 1.7794 \mathrm{MW}$, respectively. The $\dot{E}_{\mathrm{F}, \text { System }} / \dot{E}_{\mathrm{P}, \text { System }}$ values are $22.2858 / 14.4942$ and $21.0311 /$ 15.0243 WM, respectively. Thus, the $\dot{E}_{\mathrm{D}, \text { System }}$ values are 7.7916 and $6.0067 \mathrm{MW}$, respectively. The $\varepsilon_{\mathrm{System}}$ values are 65.04 and $71.44 \%$, respectively, while the $\eta_{\text {System }}$ values are 21.29 and $21.65 \%$, respectively. It can be verified that the $\varepsilon_{\text {System }} / \eta_{\text {System }}$ in 


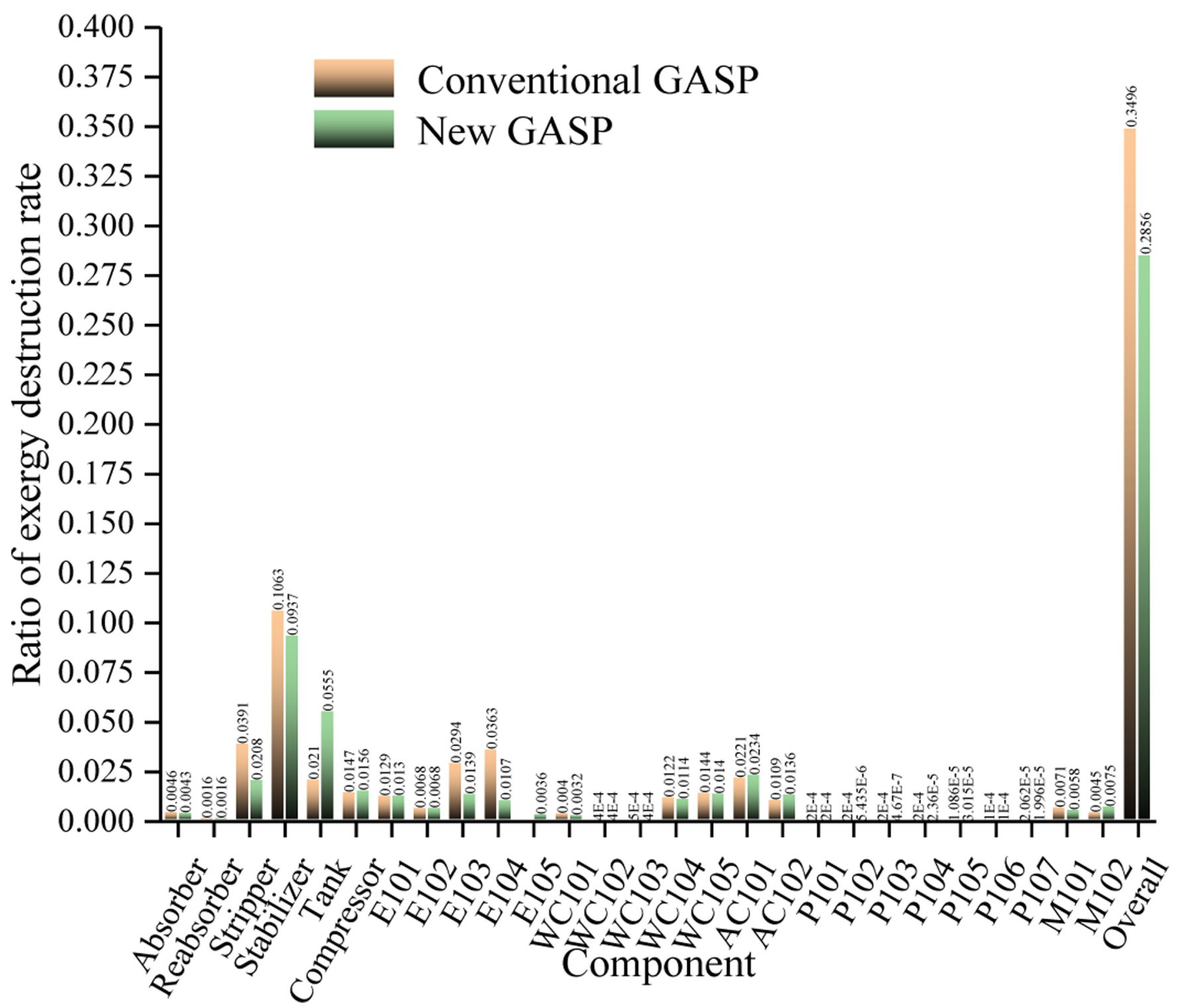

Figure 8. Ratios of exergy destruction rate within the components to the exergy rate of the feed in conventional and new GASPs.

the new GASP is improved by $6.40 \% / 0.36 \%$ because the energy consumption is reduced by $5.20 \%$. It is clear from Table S4 that 34.96 and $28.56 \%$ of the total input exergy of the feed are destroyed, respectively. Therefore, the energy performance of the new GASP is better than that of the conventional GASP.

The exergy destruction ratios for components in the conventional and new GASPs are shown in Figure 5. The stabilizer has the largest exergy destruction ratio of the overall system due to relatively large reflux ratio (RR) in terms of the separation between the LPG and stable gasoline. Compared with the conventional GASP, the exergy destruction ratio is increased from 30.39 to $31.53 \%$ in the new GASP. However, the $\dot{E}_{\mathrm{D}, k}$ value decreases from 2.3682 to $1.9700 \mathrm{MW}$ (see Figure S3). In the conventional GASP, the exergy is mainly destroyed in several components including the stabilizer, stripper, E103, and E104. At the same time, the exergy is mainly destroyed in several components including the stabilizer, stripper, tank, AC101, and compressor in the new GASP. Both in the conventional and new GASPs, the $\dot{E}_{\mathrm{D}, k}$ of water coolers and pumps can be ignored because they are small compared with other components.
Based on the balance of feed and product exergies, the $\varepsilon_{k}$ for components are presented in Figure 6 for the conventional and new GASPs. The $\varepsilon_{\text {System }}$ of conventional and new GASPs are 65.04 and $71.44 \%$, respectively. Obviously, the energy efficiency has been significantly improved by $6.40 \%$. The highest $\varepsilon_{\text {Compressor }}$ is $85.26 \%$ in the conventional GASP, while the highest $\varepsilon_{\mathrm{E} 104}$ is $92.43 \%$ in the new GASP. It is mentioned that the $\varepsilon_{\mathrm{E} 104}$ is significantly improved because of the decrease of $\dot{E}_{\mathrm{D}, k}$ from 0.8081 to $0.2246 \mathrm{MW}$. Although the $\varepsilon_{k}$ of water coolers and pumps is significantly improved, it is not a priority to improve these components considering the small $\dot{E}_{\mathrm{D}, k}$. Based on the balance of input and output exergies, the $\eta_{k}$ for components are shown in Figure 7 for the conventional and new GASPs. The $\eta_{\text {System }}$ of conventional and new GASPs are 21.29 and $21.65 \%$, respectively. The energy efficiency has been slightly improved by $0.36 \%$. The increase of $\eta_{\text {System }}$ is obviously less than that of $\varepsilon_{\text {System }}$ because $\dot{E}_{\mathrm{F}, \text { System }}$ is much more than $\dot{E}_{\text {input,System }}$. The highest $\eta_{\mathrm{P} 101}$ is $99.98 \%$ both in the conventional and new GASPs. It is shown that the $\eta_{\text {Stripper }}$ is significantly improved from 61.79 to $76.22 \%$ because $\dot{E}_{\mathrm{D}, k}$ is decreased from 0.8716 to $0.4367 \mathrm{MW}$. 
Figure 8 presents the ratios of exergy destructions within the components to the total exergy destruction of the system in the conventional and new GASPs. Compared with the conventional GASP, the $y_{\text {System }}$ is decreased by $6.41 \%$ in the new GASP. The $y_{\text {Stabilizer }}$ values are 10.63 and $9.37 \%$, respectively, which are the largest in both conventional and new GASPs. Compared with the conventional GASP, the $y_{k}$ values are significantly decreased in the stripper, E103, and E104. It indicates that reversibilities of these components are improved relatively. It is worth noting that the $y_{\text {Stabilizer }}$ value of the new GASP is increased by $3.45 \%$, which is different from other components. It shows that there is a high potential to reduce the exergy destruction of the stabilizer in the new GASP.

4.3. Results of Advanced Exergy Analysis. The conventional exergy analysis is capable of calculating the exergy destruction rates of components in the system. However, it cannot exactly identify the sources of irreversibilities and real improvement potentials. Using the advanced exergy analysis, all parts of exergy destruction within each component of conventional and new GASPs can be evaluated. The ROC, UOC, and TOC of different components for GASPs are shown in Table S1, and results from advanced exergy analysis are given in Table S5. For the overall system, both $\dot{E}_{\mathrm{D}, S y s t e m}^{\mathrm{AV}} / \dot{E}_{\mathrm{D}, \text { System }}^{\mathrm{UN}}$ and $\dot{E}_{\mathrm{D}, \text { System }}^{\mathrm{EN}} /$ $\dot{E}_{\mathrm{D}, \text { System }}^{\mathrm{EX}}$ are all reduced in the new GASP. $\dot{E}_{\mathrm{D}, \text { System }}^{\mathrm{EN}}$ is slightly more than $\dot{E}_{\mathrm{D}, \text { System; }}^{\mathrm{AV}}$ however, $\dot{E}_{\mathrm{D}, \text { System }}^{\mathrm{EX}}$ is slightly less than $\dot{E}_{\mathrm{D}, \text { System. }}^{\mathrm{UN}} \cdot \dot{E}_{\mathrm{D}, \text { System }}^{\mathrm{AV}}$ is decreased from 3.6133 to $2.4463 \mathrm{MW}$ because of process innovation. Therefore, new exergy parameters appear to be the key indicators to show how much the system could be improved. 46.37 and $40.73 \%$ for the total exergy destruction can be reduced in the conventional and new GASPs, respectively. Meanwhile, $\dot{E}_{\mathrm{D}, \mathrm{System}}^{\mathrm{UN}}$ is reduced by 0.6178 $\mathrm{MW}$ in the new GASP. The $\dot{E}_{\mathrm{D}, \mathrm{System}}^{\mathrm{EN}}$ values are $3.8138 \mathrm{MW}$ and 3.5605 , respectively, for the conventional and new GASPs, which is mainly from the stripper and stabilizer. The variation tendency is similar to the avoidable and unavoidable parts. The $\dot{E}_{\mathrm{D}, \text { System }}^{\mathrm{EN}}$ value decreased by $0.2533 \mathrm{MW}$, and the $\dot{E}_{\mathrm{D}_{2} \text { System }}^{\mathrm{EX}}$ value decreased by $0.9118 \mathrm{MW}$. The ratios of $\dot{E}_{\mathrm{D}, \text { System }}^{\mathrm{EN}}$ to $E_{\mathrm{D}, \text { System }}$ are 48.96 and $51.04 \%$ in the conventional and new GASPs, respectively. The energy improvement potential remains unchanged from the view of the endogenous/exogenous exergy destructions concept.

Figure 9 shows the avoidable and unavoidable exergy destruction rates for components in the conventional and new GASPs. The top 10 components of avoidable and unavoidable exergy destruction rates of the system are given in Table 3. There is a small deviation for the main contributions of $\dot{E}_{\mathrm{D}, \text { System }}^{\mathrm{AV}}$ in the conventional and new GASPs. The air cooler of the rich gas has the largest avoidable exergy destruction rate in the new GASP. However, the enhancement efforts should be made not only to its endogenous irreversibilities but also to inefficiencies of the remaining components. The main contributions of $\dot{E}_{\mathrm{D}, \mathrm{System}}^{\mathrm{UN}}$ are similar for the conventional and new GASPs. The reasons are summarized as follows: (1) $\dot{E}_{\mathrm{D}, \text { Stabilizer }}^{\mathrm{UN}}$ and $\dot{E}_{\mathrm{D}, \text { Stripper }}^{\mathrm{UN}}$ are caused by the liquid reflux (RR) in the distillation process; (2) $\dot{E}_{\mathrm{D}, \mathrm{Absorber}}^{\mathrm{UN}}$ is caused by the liquid-vapor ratio $(L / V)$ in the absorption process; (3) $\dot{E}_{\mathrm{D}, \mathrm{Tank}}^{\mathrm{UN}}$ and $\dot{E}_{\mathrm{D}, \mathrm{M} 101}^{\mathrm{UN}}\left(\dot{E}_{\mathrm{D}, \mathrm{M} 102}^{\mathrm{UN}}\right)$ are caused by process irreversibilities in the flash and mixer; and (4) $\dot{E}_{\mathrm{D}, \mathrm{WC} 104}^{\mathrm{UN}}$ is caused by the minimal heat transfer temperature approach in the heat exchanger. Some $\dot{E}_{\mathrm{D}, k}^{\mathrm{AV}}$ can be ignored including columns, pumps, and mixers, while some $\dot{E}_{\mathrm{D}, k}^{\mathrm{UN}}$ can be ignored including the tank, the compressor, heat exchangers, air coolers, water coolers, and pumps.

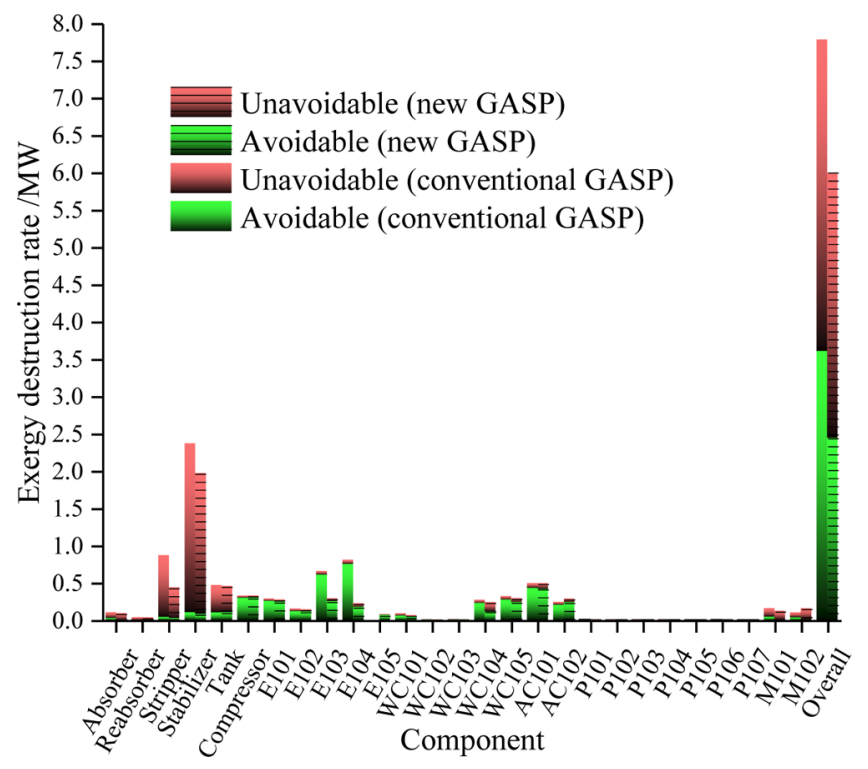

Figure 9. Avoidable and unavoidable exergy destruction rates for components in conventional and new GASPs.

Figure 10 shows endogenous and exogenous exergy destruction rates for components in the conventional and new GASPs. The top 10 components of endogenous and exogenous exergy destruction rates of the system are given in Table 4 . There is no obvious difference for the main contributions of $\dot{E}_{\mathrm{D} \text {,System }}^{\mathrm{EN}}$ in the conventional and new GASPs. In comparison with the conventional GASP, the largest $\dot{E}_{\mathrm{D}, \text { Stabilizer }}^{\mathrm{EN}}$ is decreased by 0.4240 WM for the new GASP. The main contributions of $\dot{E}_{\mathrm{D}, \text { System }}^{\mathrm{EX}}$ are almost the same in both conventional and new GASPs. The largest $\dot{E}_{\mathrm{D}, \mathrm{AC} 101}^{\mathrm{EX}}$ is $0.4637 \mathrm{WM}$ for the new GASP, while the largest $\dot{E}_{\mathrm{D}, \mathrm{E} 104}^{\mathrm{EX}}$ is $0.7858 \mathrm{WM}$ for the conventional GASP. Some $\dot{E}_{\mathrm{D}, k}^{\mathrm{EN}}$ can be ignored including the compressor, heat exchangers, air coolers, water coolers, and pumps, while some $\dot{E}_{\mathrm{D}, k}^{\mathrm{EX}}$ can be ignored including columns, pumps, and mixers.

4.4. Comparison of Advanced Exergy Analysis for Conventional and New GASPs. After splitting exergy destruction into unavoidable/avoidable and exogenous/endogenous parts as shown in Figure 11, we obtain that the ratios of

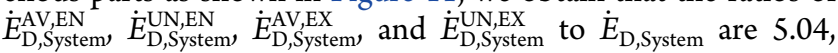
$46.01,35.69$, and $13.27 \%$, respectively, in the new GASP, while they are 5.23, 43.72, 41.15, and $9.90 \%$ in the conventional GASP. For both the conventional and new GASPs, $\dot{E}_{\mathrm{D}, S y s t e m}^{\mathrm{UN}, \mathrm{EN}}$ and $\dot{E}_{\mathrm{D}, \text { System }}^{\mathrm{AV}, \mathrm{EX}}$ have the largest proportion. For the overall system, it is clear that $\dot{E}_{\mathrm{D}, \text { System }}^{\mathrm{AV}, \mathrm{EX}}$ and $\dot{E}_{\mathrm{D}, \text { System }}^{\mathrm{UN}, \mathrm{EX}}$ have slightly changed. However, the sum of these two exergy destruction parts is basically unchanged. The top 10 components of avoidable/unavoidable and endogenous/exogenous exergy destruction rates of the system are given in Table 5. For the four parts of the exergy destruction rates, the overwhelming majority of the exergy destruction rates is all from the top 10 components. The main resources of $\dot{E}_{\mathrm{D}, \mathrm{System}}^{\mathrm{AV}, \mathrm{EN}} \dot{E}_{\mathrm{D}, k}^{\mathrm{UN}, \mathrm{EN}}$, and $\dot{E}_{\mathrm{D}, k}^{\mathrm{UN}, \mathrm{EX}}$ are similar in both conventional and new GASPs. It should be mentioned that the largest contributions of $\dot{E}_{\mathrm{D}, k}^{\mathrm{UN}, \mathrm{EN}}$ are the stabilizer and the stripper. However, as the main resources of $\dot{E}_{\mathrm{D}, \mathrm{System}}^{\mathrm{AV}, \mathrm{BN}}$, these components are still the potential improved units.

From the results shown in Figure 11, the following conclusions can be made: (1) for $\dot{E}_{\mathrm{D}, \text { System }}^{\mathrm{AV} \text {,EN }}$ in both conventional and new GASPs, the major contributors are the stabilizer and tank, in which the ratios of $\dot{E}_{\mathrm{D}, k}^{\mathrm{AV}, \mathrm{EN}}$ to $\dot{E}_{\mathrm{D}, \text { System }}^{\mathrm{AV}, \mathrm{EN}}$ are 39.66 and $45.75 \%$; (2) for $\dot{E}_{\mathrm{D}, \mathrm{System}}^{\mathrm{UN}, \mathrm{EN}}$, the main resources are similar in the 
Table 3. Main Resources of Avoidable and Unavoidable Exergy Destruction Rates

\begin{tabular}{|c|c|c|c|c|c|c|c|}
\hline \multicolumn{4}{|c|}{ conventional GASP } & \multicolumn{4}{|c|}{ new GASP } \\
\hline$k$ & $\dot{E}_{\mathrm{D}, k}^{\mathrm{AV}} / \dot{E}_{\mathrm{D}, \text { System }}^{\mathrm{AV}}(\%)$ & $k$ & $\dot{E}_{\mathrm{D}, k}^{\mathrm{UN}} / \dot{E}_{\mathrm{D}, \text { System }}^{\mathrm{UN}}(\%)$ & $k$ & $\dot{E}_{\mathrm{D}, k}^{\mathrm{AV}} / \dot{E}_{\mathrm{D}, \text { System }}^{\mathrm{AV}}(\%)$ & $k$ & $\dot{E}_{\mathrm{D}, k}^{\mathrm{UN}} / \dot{E}_{\mathrm{D}, \text { System }}^{\mathrm{UN}}(\%)$ \\
\hline E104 & 20.83 & stabilizer & 54.14 & AC101 & 17.23 & stabilizer & 53.05 \\
\hline E103 & 16.89 & stripper & 19.88 & compressor & 12.33 & stripper & 11.60 \\
\hline AC101 & 11.90 & $\operatorname{tank}$ & 8.78 & E103 & 10.40 & $\operatorname{tank}$ & 9.83 \\
\hline compressor & 8.29 & M101 & 2.75 & E101 & 10.07 & M102 & 4.37 \\
\hline WC105 & 7.60 & absorber & 1.78 & WC105 & 9.90 & WC104 & 3.51 \\
\hline E101 & 7.15 & M102 & 1.59 & AC102 & 9.81 & M101 & 3.36 \\
\hline WC104 & 6.35 & $\mathrm{AC} 101$ & 1.50 & E104 & 7.14 & absorber & 2.55 \\
\hline $\mathrm{AC} 102$ & 5.66 & E104 & 1.33 & E102 & 4.76 & AC101 & 1.99 \\
\hline E102 & 3.32 & WC105 & 1.11 & WC104 & 4.68 & WC105 & 1.46 \\
\hline stabilizer & 2.94 & E103 & 1.11 & $\operatorname{tank}$ & 4.35 & E104 & 1.40 \\
\hline total & 90.92 & total & 93.96 & total & 90.68 & total & 93.12 \\
\hline
\end{tabular}

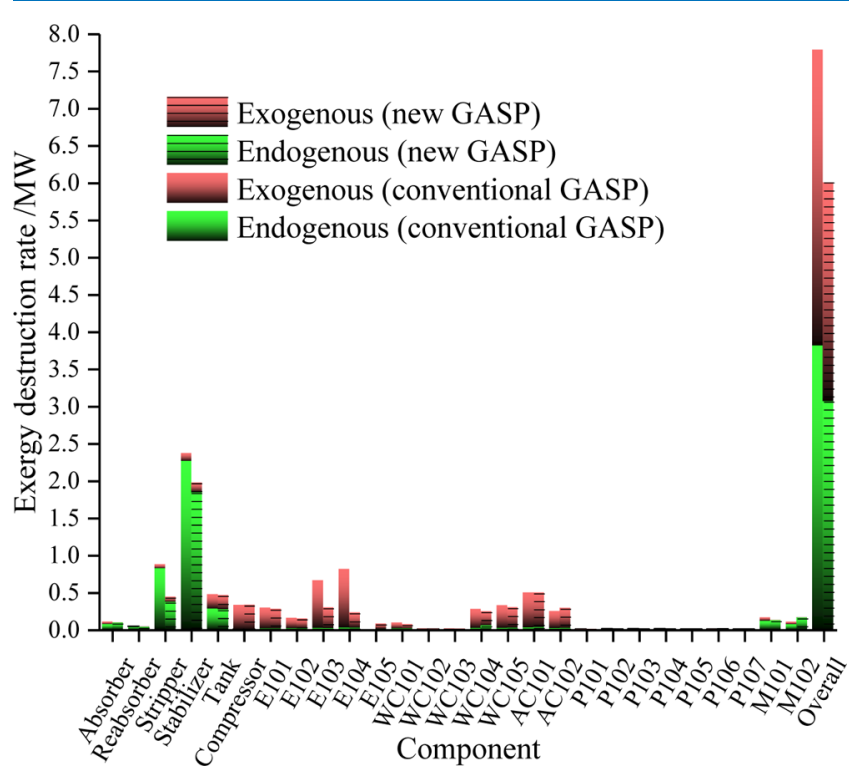

Figure 10. Endogenous and exogenous exergy destruction rates for components in conventional and new GASPs.

conventional and new GASPs. The major contributors are the stabilizer, stripper, and tank, in which ratios of $\dot{E}_{\mathrm{D}, k}^{\mathrm{AV}, \mathrm{EN}}$ to $\dot{E}_{\mathrm{D}, \mathrm{System}}^{\mathrm{AV}}$ are 92.82 and $83.81 \%$, respectively; (3) for $\dot{E}_{\mathrm{D}, \mathrm{AV} \text { System }}^{\mathrm{AV}, k}$ the main sources are different in the conventional and new GASPs. For the conventional GASP, the major contributors are the AC101, compressor, and E103, in which the ratio of $\dot{E}_{\mathrm{D}, k}^{\mathrm{AV}, \mathrm{EX}}$ to $\dot{E}_{\mathrm{D}, \mathrm{System}}^{\mathrm{A}, \mathrm{EX}}$ $40.55 \%$. For the new GASP, the major contributors are the

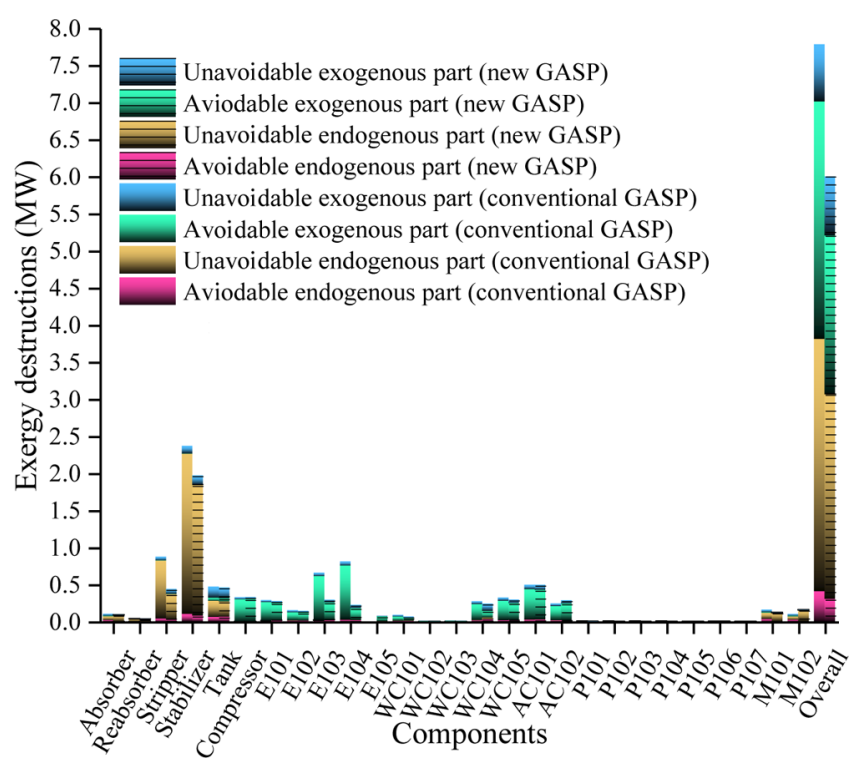

Figure 11. Exergy destruction rates for components combined with avoidable/unavoidable and endogenous/exogenous concepts in conventional and new GASPs.

$\mathrm{AC} 101$, compressor, E103, and E101, in which the ratio of $\dot{E}_{\mathrm{D}, k}^{\mathrm{AV}, \mathrm{EX}}$ to $\dot{E}_{\mathrm{D}, \mathrm{System}}^{\mathrm{AV}, \mathrm{EX}}$ is $54.86 \%$; (4) for $\dot{E}_{\mathrm{D}, \mathrm{System}}^{\mathrm{UN}, \mathrm{EX}}$ the main sources are similar in the conventional and new GASPs. The major contributors are the tank, the stabilizer, and AC101, in which the ratios of $\dot{E}_{\mathrm{D}, k}^{\mathrm{UN}, \mathrm{EX}}$ to $\dot{E}_{\mathrm{D}, \mathrm{System}}^{\mathrm{UN}, \mathrm{EX}}$ are 39.85 and $42.24 \%$, respectively.

Table 4. Main Resources of Endogenous and Exogenous Exergy Destruction Rates

\begin{tabular}{|c|c|c|c|c|c|c|c|}
\hline \multicolumn{4}{|c|}{ conventional GASP } & \multicolumn{4}{|c|}{ new GASP } \\
\hline$k$ & $\dot{E}_{\mathrm{D}, k}^{\mathrm{EN}} / \dot{E}_{\mathrm{D}, S y s t e m}^{\mathrm{EN}}(\%)$ & $k$ & $\dot{E}_{\mathrm{D}, k}^{\mathrm{EX}} / \dot{E}_{\mathrm{D}, \text { System }}^{\mathrm{EX}}(\%)$ & $k$ & $\dot{E}_{\mathrm{D}, k}^{\mathrm{EN}} / \dot{E}_{\mathrm{D}, \text { System }}^{\mathrm{EN}}(\%)$ & $k$ & $\dot{E}_{\mathrm{D}, k}^{\mathrm{EX}} / \dot{E}_{\mathrm{D}, \text { System }}^{\mathrm{EX}}(\%)$ \\
\hline stabilizer & 59.34 & E104 & 19.75 & stabilizer & 59.99 & AC101 & 15.77 \\
\hline stripper & 21.51 & E103 & 16.03 & stripper & 11.98 & compressor & 11.18 \\
\hline $\operatorname{tank}$ & 7.32 & $\mathrm{AC} 101$ & 11.75 & $\operatorname{tank}$ & 8.73 & E103 & 9.43 \\
\hline M101 & 2.99 & compressor & 8.21 & M102 & 5.06 & WC105 & 9.29 \\
\hline absorber & 1.75 & WC105 & 7.60 & M101 & 3.89 & AC102 & 9.10 \\
\hline M102 & 1.73 & E101 & 6.94 & absorber & 2.86 & E101 & 8.92 \\
\hline reabsorber & 0.92 & WC104 & 6.41 & WC104 & 1.65 & E104 & 6.95 \\
\hline AC101 & 0.66 & AC102 & 5.71 & reabsorber & 1.04 & WC104 & 6.43 \\
\hline E104 & 0.59 & $\operatorname{tank}$ & 4.75 & AC101 & 0.93 & $\operatorname{tank}$ & 6.42 \\
\hline WC105 & 0.49 & E102 & 3.49 & WC105 & 0.68 & E102 & 4.48 \\
\hline total & 97.30 & total & 90.63 & total & 96.82 & total & 87.96 \\
\hline
\end{tabular}



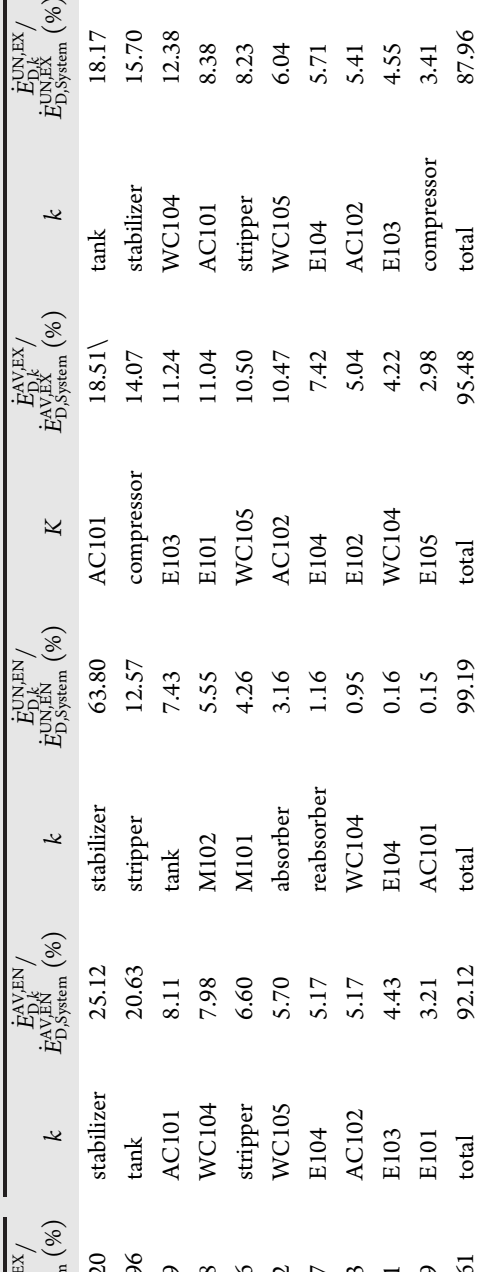

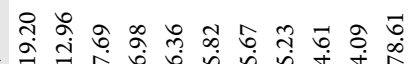
.1요

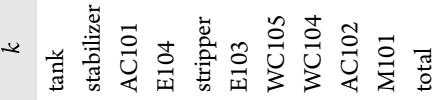

के

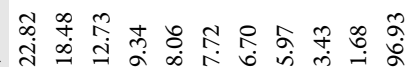
खर्म

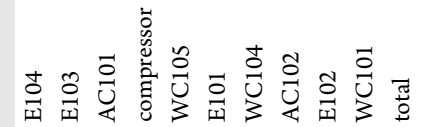

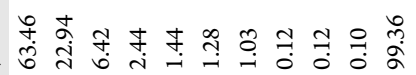
so

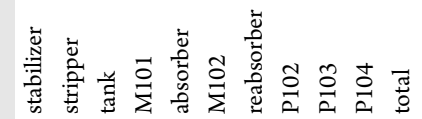

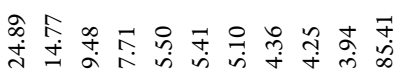
xit

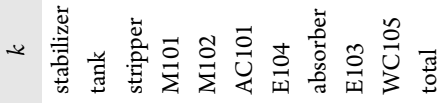

4.5. Sensitivity Analysis. In order to investigate the characteristics of exergy destruction, it is beneficial to conduct a sensitivity analysis to find the optimal important operating parameters. The significant difference is the retrofit of the side draw stream in the absorber between the conventional and new GASPs. For the side draw stream, the flow rate and location are critical designing and operating parameters in the absorber. The exergy destruction rate depends on the mass flow rate through the component and the specific entropy generation within it. The entropy generation is also decided by the flow rate and location of the side draw stream. Moreover, for this study, conventional and advanced exergy analyses are used to reveal some significant information on the effects of system's component interactions and the resulting dependency of a component's efficiency on the performance of itself and other components. As a result, the effects of flow rate and the location of the side draw stream are considered in sensitivity analysis. The exergy efficiencies and exergy destruction rates of the absorber are selected as variables to be studied individually.

The effects of the flow rate of the side draw stream on the conventional and advanced exergy analyses of the absorber are shown in Figure 12. The overall exergy destruction of the absorber increases first and then decreases as the increase of the flow rate of the side draw stream. When the flow rate of the side draw stream is $95 t / h$, the exergy efficiency reaches its maximum $(72.80 \%)$ as the exergy destruction rate reaches its minimum $(0.0908 \mathrm{MW})$. The reason is that the liquid distribution is varied with a flow rate of the side draw stream. Besides, the mass and heat are transferred in the countercurrent flow between the vapor and liquid, which results in exergy destruction. The variation tendencies of $\dot{E}_{\mathrm{D}, k}^{\mathrm{UN}}, \dot{E}_{\mathrm{D}, k}^{\mathrm{EN}}$ and $\dot{E}_{\mathrm{D}, k}^{\mathrm{UN}, \mathrm{EN}}$ are similar to that of $\dot{E}_{\mathrm{D}, k}$ effected by the flow rate of the side draw stream. Meanwhile, the variation tendencies of $\dot{E}_{\mathrm{D}, k}^{\mathrm{EX}}$ and $\dot{E}_{\mathrm{D}, k}^{\mathrm{UN}, \mathrm{EX}}$ are consistent. Little of exergy destruction rates including $\dot{E}_{\mathrm{D}, k}^{\mathrm{AV}}, \dot{E}_{\mathrm{D}, k}^{\mathrm{AV}, \mathrm{EN}}$, and $\dot{E}_{\mathrm{D}, k}^{\mathrm{AV}, \mathrm{EX}}$ remained, which can be ignored for improving the energy performance. The exergy efficiency is relatively increased through varying the flow rate of the side draw stream. However, as indicated by $\dot{E}_{\mathrm{D}, k}^{\mathrm{AV}}$, the actual energy-saving potential through optimizing the flow rate of the side draw stream seems low. $\dot{E}_{\mathrm{D}, k}^{\mathrm{EN}}$ is the lowest when the exergy efficiency is at its maximum, which is different from $\dot{E}_{\mathrm{D}, k}^{\mathrm{EX}}$.

The effects of the location of the side draw stream on conventional and advanced exergy analysis of the absorber is shown in Figure 13. The overall exergy destruction of the absorber increases first and then decreased as the location of the side draw stream increases. When the location of the side draw stream is the 11th tray, the exergy efficiency reaches its maximum (72.69\%) as exergy destruction is at its minimum $(0.0906 \mathrm{MW})$, which is similar to the result for the analysis of the flow rate of the side draw stream. The reason is that the liquid distribution is varied with the location of the side draw stream. In addition, exergy destruction is caused by the mass and heat transfer in the countercurrent flow between the vapor and liquid. The variation tendencies of $\dot{E}_{\mathrm{D}, k}^{\mathrm{AV}}, \dot{E}_{\mathrm{D}, k}^{\mathrm{EX}}$, and $\dot{E}_{\mathrm{D}, k}^{\mathrm{UN}, \mathrm{EX}}$ are similar to that of $\dot{E}_{\mathrm{D}, k}$ effected by the location of the side draw stream. Meanwhile, the variation tendencies of $\dot{E}_{\mathrm{D}, k}^{\mathrm{AV}}, \dot{E}_{\mathrm{D}, k}^{\mathrm{EX}}, \dot{E}_{\mathrm{D}, k}^{\mathrm{AV}, \mathrm{EN}}$, and $\dot{E}_{\mathrm{D}, k}^{\mathrm{UN}, \mathrm{EX}}$ are consistent. $\dot{E}_{\mathrm{D}, k}^{\mathrm{AV}, \mathrm{EX}}$ are very little, which can be ignored for improving the energy performance. The exergy efficiency is increased through varying the location of the side draw stream. Moreover, the actual energy-saving potential indicated by $\dot{E}_{\mathrm{D}, k}^{\mathrm{AV}}$ is high to optimize the location of the side draw stream. $\dot{E}_{\mathrm{D}, k}^{\mathrm{EX}}$ is the lowest when the exergy efficiency is reaching to the highest, 


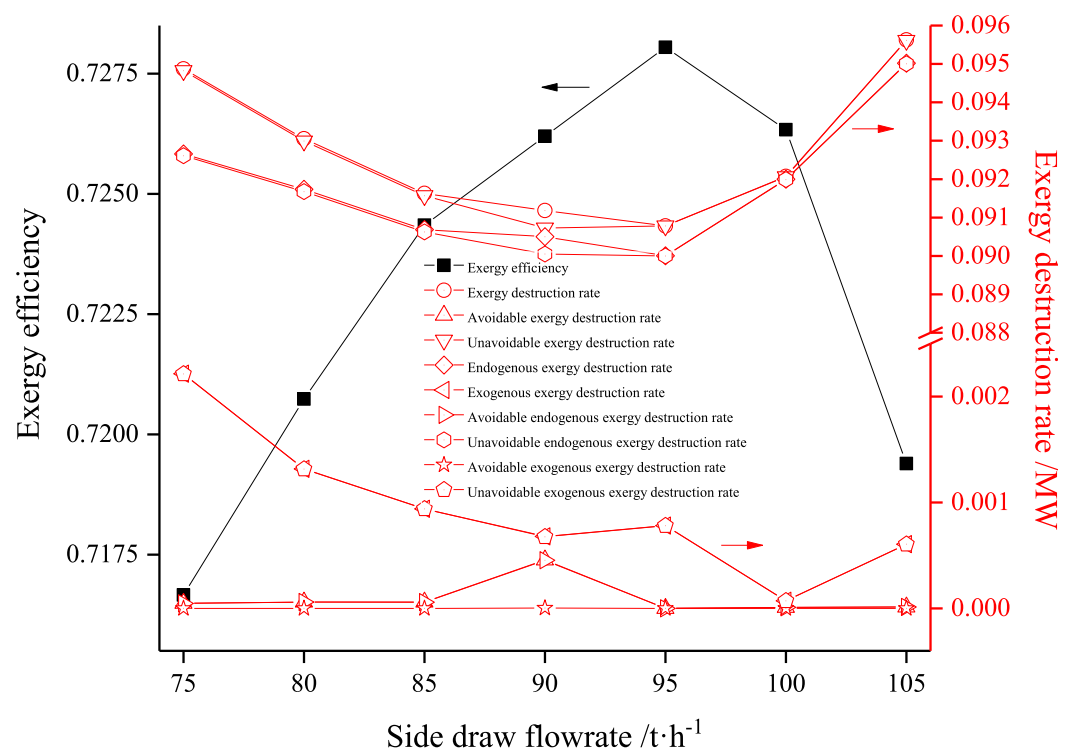

Figure 12. Effects of the flow rate of the side draw stream on the conventional and advanced exergy analyses of the absorber in the new GASP.

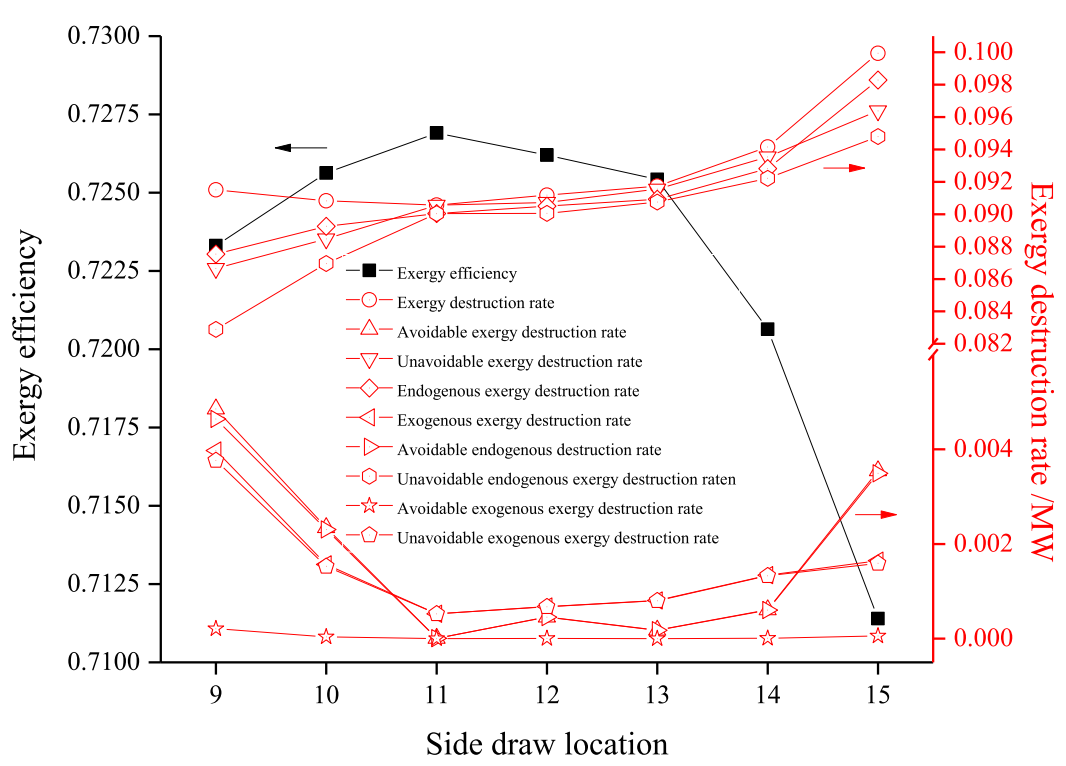

Figure 13. Effects of the location of the side draw stream on the conventional and advanced exergy analyses of the absorber in the new GASP.

which is different from $\dot{E}_{\mathrm{D}, k}^{\mathrm{EN}}$. It is contrary to the sensitive analysis of the side draw flow rate.

\section{CONCLUSIONS}

A new GASP for improved energy utilization considering the absorption process intensification is proposed and evaluated using exergy analysis in this work. The most critical feature of the new process is the retrofit of the side draw stream to improve the absorption performance. The advanced exergy analysis can be used to evaluate and understand the new GASP thoroughly combined with the conventional exergy analysis. Some detailed and useful information are obtained through the advanced exergy analysis and the comparative analysis, which can be used to identify the energy utilization bottleneck for system improvement. Three-layer conclusions are listed as follows:

(1) Compared with the conventional GASP, the energy consumption of the new GASP is reduced by $5.20 \%$. The main cause is that repeated cooling and heating of components $\mathrm{C}_{3}-\mathrm{C}_{5}$ is decreased to reduce the reboiler heat duty of the stripper significantly.

(2) The new GASP has a better thermodynamic performance compared with the conventional GASP. The stabilizer has the largest ratio of exergy destruction to the total exergy destruction of the system corresponding to 30.39 and $32.80 \%$ for the conventional and new GASPs, respectively.

$\dot{E}_{\mathrm{D}, \text { System }}^{\mathrm{AV}}$ is decreased from 3.61 to $2.45 \mathrm{MW}$ after the process innovation. 46.37 and $40.73 \%$ of the total exergy destructions can be reduced in the conventional and new GASPs, respectively. The main contributions come from the absorber, stripper, stabilizer, and some specific heat exchangers. In the new GASP, though the stabilizer has the largest exergy destruction, the air cooler of the rich gas has the largest avoidable exergy destruction, which is different from the conventional GASP. However, the enhancement efforts should be made not only to its endogenous irreversibilities but also to inefficiencies of the remaining components. $\dot{E}_{\mathrm{D} \text {,System }}^{\mathrm{EN}}$ is decreased from 3.81 to 3.56 
MW in the new GASP compared with the conventional GASP, which is mainly from the stripper and stabilizer. $\dot{E}_{\mathrm{D}, \mathrm{System}}^{\mathrm{UN}, \mathrm{EN}}$ and $\dot{E}_{\mathrm{D}, \text { System }}^{\mathrm{AV}} \mathrm{EX}$ have the largest proportion in both conventional and new GASPs. The ratios are 51.04 and $48.96 \%$ in the new GASP, while they are 43.72 and $41.15 \%$ in the conventional GASP. For $\dot{E}_{\mathrm{D}, \mathrm{System}}^{\mathrm{UN}, \mathrm{EN}}$, the main source is the stabilizer. For $\dot{E}_{\mathrm{D}, \mathrm{System}}^{\mathrm{AV}, \mathrm{EX}}$, the main sources are reboilers of the stripper and stabilizer, the air cooler of the rich gas and compressor.

(3) The sensitivity analysis shows that optimizing the flow rate and location of the side draw stream is the efficient way to improve the exergy efficiency of the absorber in terms of reducing $\dot{E}_{\mathrm{D}, \mathrm{Absorber}}^{\mathrm{AV}}$ and $\dot{E}_{\mathrm{D}, \mathrm{Absorber}}^{\mathrm{EX}}$. As indicated by $\dot{E}_{\mathrm{D}, \mathrm{Abs} \text { ( }}^{\mathrm{AV}}$, the actual energy-saving potential is higher by optimizing the location of the side draw stream than varying the flow rate of the side draw stream. $\dot{E}_{\mathrm{D} \text {,Absorber }}^{\mathrm{EX}}$ is in the lowest when the exergy efficiency reaches to the maximum, which is different from $\dot{E}_{\mathrm{D}, \mathrm{Abs}}^{\mathrm{EN}}$. The results are entirely different in the sensitivity analysis of the side draw flow rate and location.

\section{ASSOCIATED CONTENT}

\section{SI Supporting Information}

The Supporting Information is available free of charge at https://pubs.acs.org/doi/10.1021/acsomega.1c01658.

Real unavoidable and theoretical operation conditions for components of conventional and new GASPs; tray data, specification, and variable parameters of columns; main parameters in the simulation; results of conventional and advanced exergy analysis of conventional and new GASPs; main energy consumption components; vaporliquid duty of stages in the stripper; and exergy destruction rates for components in conventional and new GASPs (XLSX)

\section{AUTHOR INFORMATION}

\section{Corresponding Authors}

Yang Lei - School of Chemistry and Chemical Engineering, Hubei Key Laboratory of Coal Conversion and New Carbon Materials, Wuhan University of Science and Technology, Wuhan, Hubei 430081, China; Center for Energy Resources Engineering, Department of Chemistry, Technical University of Denmark, Lyngby 2800, Denmark; ㅇorcid.org/0000-00021975-3569; Email: leiyang@wust.edu.cn,yanglei@ kemi.dtu.dk

Wei Yan - Center for Energy Resources Engineering, Department of Chemistry, Technical University of Denmark, Lyngby 2800, Denmark; 이이이.org/0000-0002-88102479; Email: weya@kemi.dtu.dk

\section{Authors}

Yuqiu Chen - Department of Chemical and Biochemical Engineering, Technical University of Denmark, Lyngby 2800, Denmark; 이이이.org/0000-0003-0706-160X

Yibo Yang - Center for Energy Resources Engineering, Department of Chemistry, Technical University of Denmark, Lyngby 2800, Denmark

Xinyan Liu - School of Chemistry and Chemical Engineering, Hubei Key Laboratory of Coal Conversion and New Carbon Materials, Wuhan University of Science and Technology, Wuhan, Hubei 430081, China

Hao Luo - School of Chemistry and Chemical Engineering, Hubei Key Laboratory of Coal Conversion and New Carbon
Materials, Wuhan University of Science and Technology, Wuhan, Hubei 430081, China

Complete contact information is available at:

https://pubs.acs.org/10.1021/acsomega.1c01658

Notes

The authors declare no competing financial interest.

\section{ACKNOWLEDGMENTS}

The authors are grateful for the financial support from the National Nature Science Foundation of China project (no. 21706198) and the China Scholarship Council project (no. 201908420380).

\section{NOMENCLATURE2-COL}

$\dot{E}$ rate of exergy (MW)

$P$ pressure $(\mathrm{kPa})$

$Q$ heat duty (MW)

$\mathrm{RR}$ reflux ratio

$T$ temperature (K)

$\mathrm{W}$ power (MW)

$x$ molar fraction

$y$ ratios of exergy destruction to total exergy of the feed

$y^{*}$ ratios of exergy destruction to total exergy destruction

\section{GREEK LETTERS}

$\eta$ exergy efficiency based on the input/out balance

$\varepsilon$ exergy efficiency based on the feed/product balance

$\Delta$ difference

\section{SUBSCRIPTS}

0 standard condition

AbC absorption column

Co compressor

D destruction

$\mathrm{DiC}$ distillation column

F feed

Fl flash tank

HeEx heat exchanger

$i$ component

in inlet stream

$k \quad k$ th component

L loss

Mi mixer

out output stream

$\mathrm{P}$ product

$\mathrm{Pu}$ pump

\section{SUPERSCRIPTS}

AV avoidable

ch chemical

EN endogenous

EX exogenous

mix mixture

ph physical

UN unavoidable

\section{ABBREVIATIONS}

AC air cooler

DCU delayed coking unit

FCCU fluid catalytic cracking unit

GASP gasoline absorption-stabilization process 
HE heat exchanger

LPG liquefied petroleum gas

$\mathrm{P} \quad$ pump

ROC real operation conditions

TAC total annual cost

TOC theoretical operation conditions

UOC unavoidable operation conditions

WC water cooler

\section{REFERENCES}

(1) Chen, J. Y.; Pan, M.; He, C.; Zhang, B. J.; Chen, Q. L. New gasoline absorption-stabilization process for separation intensification and flowsheet simplification in refineries. Ind. Eng. Chem. Res. 2018, 57, 14707-14717.

(2) Dudley, B. BP Statistical Review of World Energy; British Petroleum Company: U.K., 2019.

(3) Lei, Y.; Zhang, B.; Qi, X.; Chen, Q.; Hui, C.-W. Study on constraints for heat removal duties of the main fractionator in delayed coking units. Appl. Therm. Eng. 2014, 71, 573-580.

(4) Liu, X. G.; He, C.; He, C. C.; Chen, J. J.; Zhang, B. J.; Chen, Q. L. A new retrofit approach to the absorption-stabilization process for improving energy efficiency in refineries. Energy 2017, 118, 11311145.

(5) Yan, C.; Lv, L.; Wei, S. A.; Eslamimanesh, A.; Shen, W. Application of retrofitted design and optimization framework based on the exergy analysis to a crude oil distillation plant. Appl. Therm. Eng. 2019, 154, 637-649.

(6) Chen, Q. L.; Yin, Q. H.; Hua, B. An exergoeconomic approach for retrofit of fractionating systems. Energy 2002, 27, 65-75.

(7) Chen, Q. L.; Yin, Q. H.; Wang, S. P.; Hua, B. Energy-use analysis and improvement for delayed coking units. Energy 2004, 29, 22252237.

(8) Zhang, X.; He, X.; Gundersen, T. Post-combustion carbon capture with a gas separation membrane: parametric study, capture cost, and exergy analysis. Energy Fuels 2013, 27, 4137-4149.

(9) Petrakopoulou, F.; Tsatsaronis, G.; Morosuk, T. Evaluating the potential for improvement of an oxy-fuel power plant with $\mathrm{CO}_{2}$ capture using an advanced exergetic analysis. Energy Fuels 2013, 27, 48504858.

(10) Chang, H.; Chuang, S. C. Process analysis using the concept of intrinsic and extrinsic exergy losses. Energy 2003, 28, 1203-1228.

(11) Morosuk, T.; Tsatsaronis, G.; Zhang, C. Conventional thermodynamic and advanced exergetic analysis of a refrigeration machine using a Voorhees' compression process. Energy Convers. Manage. 2012, 60, 143-151.

(12) De Alwis, H. P. N. S.; Mohamad, A. A.; Mehrotra, A. K. Exergy analysis of direct and indirect combustion of methanol by utilizing solar energy or waste heat. Energy Fuels 2009, 23, 1723-1733.

(13) Buentello-Montoya, D.; Zhang, X. An energy and exergy analysis of biomass gasification integrated with a char-catalytic tar reforming system. Energy Fuels 2019, 33, 8746-8757.

(14) Vučković, G. D.; Stojiljković, M. M.; Vukić, M. V. First and second level of exergy destruction splitting in advanced exergy analysis for an existing boiler. Energy Convers. Manage. 2015, 104, 8-16.

(15) Li, H.; Li, G.; Yang, Q.; Zhou, H. Modelling and performance analysis of shale oil and methane cogeneration by oil shale pyrolysis integrated with pyrolysis gas methanation process. Energy Fuels 2020, 34, 11690-11698.

(16) Ehyaei, M. A.; Ahmadi, A.; Rosen, M. A. Energy, exergy, economic and advanced and extended exergy analyses of a wind turbine. Energy Convers. Manage. 2019, 183, 369-381.

(17) Xiong, J.; Zhao, H.; Zheng, C. Exergy analysis of a 600 MWe oxycombustion pulverized-coal-fired power plant. Energy Fuels 2011, 25, 3854-3864.

(18) Morosuk, T.; Tsatsaronis, G. Advanced exergy analysis for chemically reacting systems-application to a simple open gas-turbine system. Int. J. Therm. 2009, 12, 105-111.
(19) Tsatsaronis, G.; Morosuk, T. Advanced exergetic analysis of a novel system for generating electricity and vaporizing liquefied natural gas. Energy 2010, 35, 820-829.

(20) Petrakopoulou, F.; Tsatsaronis, G.; Morosuk, T.; Carassai, A. Conventional and advanced exergetic analyses applied to a combined cycle power plant. Energy 2012, 41, 146-152.

(21) Petrakopoulou, F.; Tsatsaronis, G.; Morosuk, T.; Paitazoglou, C. Environmental evaluation of a power plant using conventional and advanced exergy-based methods. Energy 2012, 45, 23-30.

(22) Hepbasli, A.; Keçebaş, A. A comparative study on conventional and advanced exergetic analyses of geothermal district heating systems based on actual operational data. Energy Build. 2013, 61, 193-201.

(23) Soltani, S.; Yari, M.; Mahmoudi, S. M. S.; Morosuk, T.; Rosen, M. A. Advanced exergy analysis applied to an externally-fired combinedcycle power plant integrated with a biomass gasification unit. Energy 2013, 59, 775-780.

(24) Yang, Y.; Wang, L.; Dong, C.; Xu, G.; Morosuk, T.; Tsatsaronis, G. Comprehensive exergy-based evaluation and parametric study of a coal-fired ultra-supercritical power plant. Appl. Energy 2013, 112, $1087-1099$.

(25) Açıkkalp, E.; Aras, H.; Hepbasli, A. Advanced exergy analysis of a trigeneration system with a diesel-gas engine operating in a refrigerator plant building. Energy Build. 2014, 80, 268-275.

(26) Açıkkalp, E.; Aras, H.; Hepbasli, A. Advanced exergy analysis of an electricity-generating facility using natural gas. Energy Convers. Manage. 2014, 82, 146-153.

(27) Chen, J.; Havtun, H.; Palm, B. Conventional and advanced exergy analysis of an ejector refrigeration system. Appl. Energy 2015, $144,139-151$.

(28) Boyaghchi, F. A.; Molaie, H. Sensitivity analysis of exergy destruction in a real combined cycle power plant based on advanced exergy method. Energy Convers. Manage. 2015, 99, 374-386.

(29) Boyaghchi, F. A.; Molaie, H. Investigating the effect of duct burner fuel mass flow rate on exergy destruction of a real combined cycle power plant components based on advanced exergy analysis. Energy Convers. Manage. 2015, 103, 827-835.

(30) Galindo, J.; Ruiz, S.; Dolz, V.; Royo-Pascual, L. Advanced exergy analysis for a bottoming organic Rankine cycle coupled to an internal combustion engine. Energy Convers. Manage. 2016, 126, 217-227.

(31) Zhu, Y.; Zhai, R.; Peng, H.; Yang, Y. Exergy destruction analysis of solar tower aided coal-fired power generation system using exergy and advanced exergetic methods. Appl. Therm. Eng. 2016, 108, 339346.

(32) Nami, H.; Nemati, A.; Fard, F. J. Conventional and advanced exergy analyses of a geothermal driven dual fluid organic Rankine cycle (ORC). Appl. Therm. Eng. 2017, 122, 59-70.

(33) Koroglu, T.; Sogut, O. S. Conventional and advanced exergy analyses of a marine steam power plant. Energy 2018, 163, 392-403.

(34) Gholamian, E.; Hanafizadeh, P.; Ahmadi, P. Advanced exergy analysis of a carbon dioxide ammonia cascade refrigeration system. Appl. Therm. Eng. 2018, 137, 689-699.

(35) Mohammadi, Z.; Fallah, M.; Mahmoudi, S. M. S. Advanced exergy analysis of recompression supercritical $\mathrm{CO}_{2}$ cycle. Energy 2019, 178, 631-643.

(36) Yan, C.; Yang, A.; Chien, I.-L.; Wei, S. A.; Shen, W.; Ren, J. Advanced exergy analysis of organic Rankine Cycles for FischerTropsch syngas production with parallel dry and steam methane reforming. Energy Convers. Manage. 2019, 199, 111963-111976.

(37) Ebrahimi, M.; Carriveau, R.; Ting, D. S.-K.; McGillis, A. Conventional and advanced exergy analysis of a grid connected underwater compressed air energy storage facility. Appl. Energy 2019, 242, 1198-1208.

(38) Ambriz-Díaz, V. M.; Rubio-Maya, C.; Ruiz-Casanova, E.; Martínez-Patiño, J.; Pastor-Martínez, E. Advanced exergy and exergoeconomic analysis for a polygeneration plant operating in geothermal cascade. Energy Convers. Manage. 2020, 203, 112227112243.

(39) Chang, H.; Li, J.-w. A new exergy method for process analysis and optimization. Chem. Eng. Sci. 2005, 60, 2771-2784. 
(40) Wei, Z.; Zhang, B.; Wu, S.; Chen, Q.; Tsatsaronis, G. Energy-use analysis and evaluation of distillation systems through avoidable exergy destruction and investment costs. Energy 2012, 42, 424-433.

(41) Yang, Q.; Qian, Y.; Kraslawski, A.; Zhou, H.; Yang, S. Advanced exergy analysis of an oil shale retorting process. Appl. Energy 2016, 165, 405-415.

(42) Mehrpooya, M.; Lazemzade, R.; Sadaghiani, M. S.; Parishani, H. Energy and advanced exergy analysis of an existing hydrocarbon recovery process. Energy Convers. Manage. 2016, 123, 523-534.

(43) Yamankaradeniz, N. Thermodynamic performance assessments of a district heating system with geothermal by using advanced exergy analysis. Renew. Energy 2016, 85, 965-972.

(44) Vatani, A.; Mehrpooya, M.; Palizdar, A. Advanced exergetic analysis of five natural gas liquefaction processes. Energy Convers. Manage. 2014, 78, 720-737.

(45) He, Q.; Liu, H.; Hao, Y.; Liu, Y.; Liu, W. Thermodynamic analysis of a novel supercritical compressed carbon dioxide energy storage system through advanced exergy analysis. Renew. Energy 2018, $127,835-849$.

(46) Ghorbani, B.; Roshani, H. Advanced exergy and exergoeconomic analysis of the integrated structure of simultaneous production of NGL recovery and liquefaction. Transp. Phenom. Nano Micro Scales 2018, 6, $8-14$.

(47) Li, G.; Liu, Z.; Liu, F.; Yang, B.; Ma, S.; Weng, Y.; Zhang, Y.; Fang, Y. Advanced exergy analysis of ash agglomerating fluidized bed gasification. Energy Convers. Manage. 2019, 199, 111952-111959. 